\title{
LA EDAD MEDIA EN LA WEB. FUENTE DE INFORMACIÓN O DE DESINFORMACIÓN
}

\author{
ANTONio MalaLana UREÑa \\ CEU-Universidad San Pablo
}

RESUMEN: El objetivo del presente estudio es observar y juzgar la presencia de la Edad Media en Internet. Así, han sido valorados, desde los directorios temáticos, pasando por las páginas especializadas, las revistas científicas, etc., hasta llegar a los web sites de los departamentos universitarios o de investigación. El propósito final es aportar una selección ordenada de aquellos recursos que han sido calificados como verdadera fuente de información bistórica.

Palabras Clave: Edad Media. Fuentes de Información Histórica. Internet.

ABSTRACT: The aim of the present study is to consider and assess the presence of the Middle Ages on the Internet. We have looked at themed sites, as well as specialist pages, academic journals etc., and also at the home-pages of university and research departments. The objective is to provide a clear selection of those resources which we consider provide reliable bistorical information.

KEY WORDS: Middle Ages, sources of historical information, history resources, Internet.

El presente trabajo tiene por objetivo configurar una recopilación de recursos que puedan clasificarse como documento, entendiendo por este «todo conocimiento fijado materialmente sobre un soporte y que puede ser utilizado para su consulta, estudio o trabajo». Estas palabras de Nuria Amat se amplían un poco más: un documento es valido cuando es original, fiable y útil ${ }^{1}$. Es decir, la originalidad y la fiabilidad van a marcar el método de trabajo, sobre todo con

1 Amat Noguera, Nuria: Documentación Científica y Nuevas Tecnologías de la Información, Madrid, Ediciones Pirámides, 1989, pp. 19-20. 
respecto a la búsqueda y a la selección de los recursos, valorando en cada caso la utilidad para la investigación de la Edad Media. Posteriormente, la organización del conjunto seleccionado se configurará en función de la actividad cotidiana del investigador.

Por otro lado, debemos reconocer la alta valoración que ha adquirido Internet en las sociedades occidentales. Pese a esta distinción no tenemos por qué aceptar la desmesurada influencia que ejerce este medio de comunicación entre los usuarios. La web no es la panacea universal de la información, es una herramienta más a sumar a los sistemas de información que se han desarrollado desde que se inventó la escritura y, con ella, aparecieran los archivos y las bibliotecas. Equivocadamente, el ciudadano medio cree que todo está en la red. Desafortunadamente, falta un porcentaje abrumador de la información, de tal manera, que si nos apoyamos en esta certeza, estaremos desinformados por defecto.

Desde un punto de vista distinto, la primera gran discordancia de la red de redes es la profusión de páginas, contabilizadas en ciento de miles, que ocultan y envuelven la información que precisamos. Ahora, la desinformación se generada por el efecto contrario: el exceso de información.

Por consiguiente, focalizaremos nuestro esfuerzo en desbrozar el bosque para liberar el acceso a los recursos que puedan catalogarse como documentos primarios o de referencia. El resultado final no será definitivo, ni concluyente, tampoco se pretende que estas sean las cualidades preferentes. Esto sería imposible, primero porque la propia tela de araña ha creado numerosos espacios invisibles a los usuarios, impidiendo llegar a todos los rincones. Después, a pesar de localizar las páginas deseadas, podemos toparnos con otras dos barreras más, la suscripción o el pago por la consulta y el idioma.

Asimismo, con demasiada frecuencia los editores de las páginas no son organizaciones, ni instituciones de referencia, sino personas con extraordinaria voluntad, pero con una formación en la materia muy desigual. Por enésima vez, nos vemos desbordados por la desinformación, ahora por la falta de calidad de los contenidos, excesivamente primarios, y, por lo general, reiterativos. A esta característica añadiremos otra nueva, demasiadas de estas páginas están hospedas en servidores generalistas, con direcciones atípicas, que en bastantes ocasiones terminan por desaparecer o, en el mejor de los casos, por congelar sus contenidos. Tras afirmar esto, sería muy sencillo establecer una correspondencia entre web personal y escasa calidad. Todo lo contrario, en ciertas ocasiones hemos conseguido consultar páginas caracterizadas por una excelente factura.

Ahora deberíamos suponer, por tanto, que son las áreas departamentales de las universidades, junto a otras instituciones, públicas y privadas, como institutos, museos, academias, etc., los que están obligados a crear sitios web que dispongan de contenidos de extraordinario calidad, que se regeneren con la suficiente frecuencia y que sean asequibles para todos los perfiles de usuarios.

Desgraciadamente, esto no es así, los peores males son: no existe un comportamiento corporativo claro, es decir, estas organizaciones no entienden una 
web como la prolongación de su trabajo grupal; las que existen son desarrolladas y actualizadas de manera individual por alguno de sus componentes. Como mal menor, a veces, aparecen los grupos o los proyectos de investigación, pero tan sólo utilizan este medio de comunicación como una forma más para promocionar dichas actividades. Por consiguiente, faltan contenidos, pero lo que es más grave falta voluntad para crearlos.

A pesar de lo afirmado hasta ahora, no pensemos, centrándonos en el caso español, que Internet y la Edad Media, recurriendo al tópico de la Edad Oscura, es un páramo. Como veremos a continuación, podemos presentar una selección de recursos de extraordinaria calidad.

Cada vez es más necesario que aparezcan investigaciones de análisis y valoración de contenidos, desechar el excesivo número de recursos con aportación cero y crear un activo de trabajos que cumplan con el verdadero objetivo de compartir el conocimiento. Por ejemplo, sería muy necesario observar cual es la contribución efectiva de las áreas departamentales de las universidades españolas, quienes son sus editores, que contenidos aportan, cual es su visibilidad, etc.

En Estados Unidos, siempre por delante en el desarrollo de Internet, la editorial The Haworth Press < http://www.haworthpress.com/> ha abierto varias publicaciones dedicadas al análisis de recursos electrónicos, como Journal of Internet Cataloging. The International Quaterly of Digital Organization, Classification and Access.

En nuestro país, de momento existen escasos estudios que tengan como objetivo la localización, valoración y clasificación de contenidos. Podemos citar una serie de ejemplos, insuficientes, que han centrado su interés en ciertos aspectos, como: la bibliografía histórica ${ }^{2}$, la arqueología ${ }^{3}$ o la literatura ${ }^{4}$. Centrándonos en la etapa medieval, Pedro Andrés Porras Arboledas 5 se sitúa como el precursor en el análisis y valoración de sitios web ${ }^{6}$. En nuestro caso ya ha existido una primera aproximación, aunque centrada desde una perspectiva docente ${ }^{7}$.

2 Rubio LiNIERS, María Cruz: «Fuentes bibliográficas para la Historia en Internet. Estado de la cuestión». La enseñanza de la Historia y las nuevas tecnologías de la información, Centro de Estudios Carlos de Amberes y CSIC, Madrid, 2001, [en línea], <http://www.moderna.ih.csic.es/fcamberes/b2intman.htm>, [consulta: 17-11-2003].

3 Jiménez Toledo, Elea e Mendoza García, Isabel: «Recursos especializados en arqueología», Recurso sobre Arqueología en Internet, Madrid, CINDOC, CSIC, 2001, pp. 93-219.

4 Aguirre Romero, Joaquín $\mathrm{M}^{\mathrm{a}}$ : «Literatura en Internet. ¿Qué encontramos en la WWW?». Espéculo: revista de estudios literarios, 6, (1997) [En línea] < http://www.ucm.es/info/especulo/ numero6/lite_www.htm >. [Consulta: 10-3-2004].

5 PORRAS ARBOLEDAS, Pedro Andrés: «El medievalismo en Internet», Medievalismo. Boletín de la SEEM, 7, 7, (1997), pp. 343-361; [en línea] http://www.ucm.es/info/hisdere/mednet/mednet.htm [consulta: 17-11-2003].

${ }^{6}$ En Italia, Roberta Fidanzia ha establecido una comparativa entre la oferta española y la del país trasalpino: «Il Medioevo in rete: un confronto tra Italia e Spagna», Resegna Storica online, 3, (2001), [en línea] < http://www.storiaonline.org/mi/rso/index_file/frame.htm> [consulta: 13-10-2003].

7 Malalana Ureña, Antonio: "Materiales disponibles en la red para la enseñanza de 
En consecuencia, La Edad Media es una etapa sensiblemente desdeñada por los creadores de contenidos. Este hecho se acentúa aún más si nos fijamos en el caso español. El usuario tiene dificultades, no sólo para acceder a los buenos recursos, sino también para esquivar las páginas carentes de valor.

En general, la producción no es muy prolija, quizá exista una directa relación entre el desinterés por evaluar contenidos y las pocas iniciativas entre los medievalistas de pro para explotar Internet como medio para divulgar el conocimiento.

La característica más arraigada en los estudios citados anteriormente es la de ordenar y enumerar, adoptando la formula de directorio o catálogo, donde se intentan recoger el mayor número de recursos posible. Como método organizativo cada item se incluye dentro de alguno de los grandes temas historiográficos, como el Islam, Las Cruzadas, Bizancio, el Temple, Leyendas Artúricas, Visigodos, Reinos Cristianos, Literatura, etc.; o, por entidades geográficas actuales como Portugal, España, Francia, etc. A continuación, al título del recurso se le añade una pequeña descripción que explique el contenido, desde una frase hasta un párrafo de cinco líneas. En la mayoría de las ocasiones se toma literalmente el texto que el propio responsable del recurso utiliza para exponer el objeto de la página. Para el resto, los copiladores aportan su versión del contenido de la web. En ambos casos falta la suficiente audacia para evaluar objetivamente el valor real de la información.

Sin entrar aún en el manejo de los directorios y catálogos, cualquier ínternauta cuenta con dos buenos buscadores, complementarios entre sí, Google <www.google.es> y All The Web <www.alltheweb.com>, junto a Yahoo $<$ http://es.yahoo.com/ y $M s n<$ http://www.msn.es/Default.asps>. Dejando a un lado los buscadores, el paso habitual es la utilización de directorios y buscadores especializados. Para estos últimos, existen pocas alternativas, entre ellas se encuentra el buscador Argos. Para los primeros disponemos de demasiadas opciones, por lo que es preciso recomendar aquellos que hagan una oferta de calidad. A partir de aquí, habría que ir saltando de lo general a los temas, y de estos a los sitios de primera categoría.

La estrategia de búsqueda ha sido la utilización del motor de búsqueda Google y la consulta, por orden, de los directorios — generales y temáticos-, de las páginas de los departamentos universitarios y de investigación, y de algunos portales temáticos o bibliotecas virtuales como la de Miguel de Cervantes. El resultado obtenido ha sido ante todo dispar y, salvando determinados ejemplos, insatisfactorio. Todos los recursos que aparecen a continuación han sido seleccionados en función de un único criterio, que el documento sea original. Después, se ha buscado la información desde tres perspectivas: localización

Historia Medieval», La enseñanza de la Historia y las nuevas tecnologías de la información, Centro de Estudios Carlos de Amberes y CSIC, Madrid, 2001, [en línea], <http://www.moderna.ih.csic.es/ fcamberes/b2mathm.htm >, [consulta: 17-11-2003]. 
de documentos de archivo y de textos contemporáneos como crónicas, textos literarios, etc., obras de referencia, como mapas y cronologías y, por supuesto, trabajos de investigación. Es decir, documentos útiles para el usuario ${ }^{8}$.

La estructura de la exposición es la siguiente: Directorios, Catálogos y Buscadores; fuentes de información documentales; obras de referencia; la bibliografía; hemeroteca; biblioteca virtual, libros electrónicos, ensayos, artículos; instituciones de investigación, grandes focos de intercambio del conocimiento; paginas web corporativas y departamentales.

\section{Directorio, Catálogos y Buscadores}

Los directorios como Yahoo, o el que ofrece el propio Google, ya no son una vía adecuada para los usuarios que quieren documentos originales. Los motores de búsqueda, como Google o Allteweb, son herramientas adecuadas, siempre y cuando sepamos diseñar las estrategias de búsqueda. Hasta que dominemos este proceso, las guías y los catálogos son los pasos intermedios apropiados para comenzar a escudriñar la Edad Media en Internet.

Tanto por la estructura en áreas de conocimiento, como su alternativa mediante áreas geográficas, The $W W W$ Virtual Library es el mejor catálogo general de recursos. Inmediatamente después ya pasamos a las guías especializadas en Edad Media. Por orden de calidad tendremos The Labyrinth, Internet Medieval Sourcebook y Netserf. El primer reflejo clarificador es la procedencia, ninguno es español, todos son anglosajones. No obstante, con respecto a nuestro país incluiremos dos buenos ejemplos: el listado de enlaces preparado por el Departamento de Historia de Medieval y Ciencias Historiográficas de la Universidad de Sevilla y el catálogo preparado, personalmente, por el profesor de la Universidad Autónoma de Madrid F. J. Villalba Ruiz de Toledo.

Desde lo general, entramos en la especialización, efecto que puede actuar favorablemente en la calidad de los recursos seleccionados. De entre los existentes es conveniente recomendar el confeccionado por Lillian von der Walde Moheno, denominado Hispanomedievalismo y dedicado a la literatura medieval, los del que tocan el Islam, como las guías del Instituto de Filología del CSIC y la titulada Internet Islamic History Soucerbook; o los referidos a Bizancio, fundamentalmente las guías editadas por Paul Halsall. Con respecto a este último, es justo alabar el extraordinario trabajo realizado para crear distintas guías temáticas para esta etapa histórica dentro del gran proyecto Internet History Sourcebooks.

Lógicamente, las guías anteriormente citadas no son los únicos referentes, exis-

8 Los datos y url. de cada una de las páginas web citadas se corresponden con la información obtenida durante los meses de octubre-noviembre de 2003 y actualizados a finales de 2005. Los textos que aparecen entrecomillados y en cursiva en las explicaciones de los contenidos son una trascripción literal de los textos aportados por los editores de los recursos. 
ten otra muchas, tanto las generadas por los departamentos universitarios, institutos de investigación, bibliotecas universitarias o de manera personal. Tampoco hay que olvidar, los recursos que desde los portales temáticos o dentro de los proyectos de investigación se añaden como una parte más de los mismos.

Como ya hemos comentado, los catálogos y las guías son una buena manera para comenzar la investigación. La calidad de cada uno de ellos va a depender de la capacidad que tengan sus creadores para mantener la frescura de la información. Crear una guía de recursos lleva mucho tiempo, si esta selecciona con criterios objetivos cada uno de ellos, necesitar todavía más horas. El trabajo no concluye aquí, a partir de ese momento, además de mantener la vigencia de todo la labor desarrollada, con la corrección de la url. o eliminación de las páginas desaparecidas, el editor tiene que volver a revisar toda la red para incorporar nuevos recursos. Resumiendo, el responsable o trabaja exclusivamente en la gestión de recursos electrónicos, o cuenta con personal a su servicio.

\subsection{Generales}

- The WWW Virtual Library < http://vlib.org/>. Este catálogo de enlaces mantenido por instituciones de Inglaterra, Suiza y Argentina permite el salto a los mejores recursos existentes en la red, con apartados específicos para la Edad Media y para regiones como Alemania, Francia, Italia y España; aunque tampoco debemos olvidar otros apartados más especializados que también deben revisarse. No obstante, contamos con WWWVL The World Wide Virtual Library History: Central Catalogue < http://vlib.iue.it/history/ index.html > y, por otro lado, dispone de ArchNet el World Wide Web Virtual Library of Archaeology < http://odur.let.rug.nl/ arge/>, específico para Europa. Calificación: excelente.

- Archaeology on the Net <http://c.webring.com/hub? ring=archonnet $>$. Aunque fundamentalmente atiende a la prehistoria y a la arqueología clásica, también dispone de un espacio para la arqueología medieval.

- Yahoo. History By Time Period <http:/dir.yahoo.com/Arts/Humanities/ History/By_Time_Period/ $>$. Calificación: acceptable.

- AulaCultura <http://www.csce.es/aulacultural/ $>$. Portal de Internet dedicado a la cultura española y desarrollado por el Centro Superior de Cultura Española. Dentro de cada área temática: arqueología, historia, arte, literatura, existen espacios dedicados a la cronología medieval. Calificación: aceptable.

\subsection{Generales de historia medieval}

- The Labyrinht Resources for Medieval Studies <http://www.georgetown. 
edu/labyrinth/index.html>. Junto a The Virtual Library: History, la Internet Medieval Sourcebook y The AARHMS Archive es uno de los mejores recursos para el conocimiento y el estudio de la Edad Media empleando Internet como fuente de información. Creada y mantenida por Martin Irvine y Deborah Everhart este sitio está auspiciado por la Universidad de Georgetown. Estructurado de una manera lógica, siguiendo un esquema de temas, acceso al documento primario y por ámbitos geográficos, destacamos los siguientes: Medieval Studies Text, Image, and Archival Database, The Labyrinth Library, Bibliographies y Medieval Iberia. Calificación: excelente.

- Internet Medieval Sourcebook <http://www.fordham.edu/halsall/sbook. html > . Creado y mantenido por Pual Halsall dentro del proyecto Internet History Sourcebooks y ubicado en Fordham Universtiy Center for Medieval Studies. Figura como otro de los sitios indispensables para la Historia Medieval. Calificación: excelente.

- Netserf. The Internet Connection for Medieval Resources $<$ http://www.netserf.org/> y < http://netserf.cua.edu/ $>$. Sitio creado y mantenido por Beau A.C. Harbin. Tiene una estructura clara de directorio general, por lo que a través de su motor de búsqueda puede funcionar como un buscador. Dispone de más de 1500 enlaces y de un glosario. Calificación: excelente.

- Explorind Ancient World Cultures. Index of Internet Resources $<$ http://eawc.evansville.edu/eawcindex.htm $>$. Este buscador ha sido creado y mantenido por Anthony F. Beavers. Su estructura permite localizar todo tipo de recursos para acceder a trabajos de investigación, cronologías, textos históricos e imágenes. Clasificación: excelente.

- Departamento de Historia Medieval y Ciencias y Técnicas Historiográficas de la Universidad de Sevilla <http://www.us.es/dhmcthus/enlaces.htm>. Hasta la fecha puede decirse que es uno de los mejores directorios confeccionados por un departamento universitario español. Calificación: excelente.

- Enlaces de historia medieval <http://www.uam.es/personal_pdi/filoyletras/ javr/enlaces.htm $>$. Catálogo de enlaces recopilado por el profesor de la Universidad Autónoma de Madrid F. Javier Villalba Ruiz de Toledo, Podemos encontrar todo tipo de enlaces: fuentes documentales, trabajos de investigación, proyectos, etc., ordenados en siete áreas: generales, España, Imperio Bizantino, Iglesia y religiosidad, occidente medieval, Islam y publicaciones periódicas. Destaca la amplitud de sitios relacionados con la historia de Bizancio. Calificación: buena.

- MED WEB. Historia Medieval http://www.geocities.com/milan313/ MEDWEB.HTML > . Sitio creado por José A. Marín R. que ha unificado recursos de todo tipo, como una colección de enlaces, textos de trabajos de investigación, documentación histórica, etc. Calificación: buena. 
- Buscopium. <http://www.metodosdebusca.com/buscopium/>. Buscador en castellano específico para la Edad Media. La información de que dispone está muy limitada: Calificación: mejorable.

- Medievalismo <http://www.medievalismo.org/principal.htm>. Página editada por Jorge Maíz Chacón, en la que podemos encontrar varios listados con enlaces a otras páginas, sitios, etc., de medievalistas, de organizaciones, de revistas; además de una serie de textos, artículos del editor y otra serie de documentos de interés para los historiadores y estudiantes. Calificación: buena

\subsection{Directorios especializados}

\section{Literatura}

- Hispanomedievalismo. Recursos en línea <http://www.waldemoheno.net/ recursos.html $>$. Directorio centrado en la literatura medieval confeccionado por Lillian von der Walde Moheno de la Universidad Autónoma Metropolitana-Iztapalapa. Calificación: excelente.

\section{Islam}

- Escuela de Estudios Árabes del C.S.I.C. <http://www.csic.es/cbic/eara/ recursos.htm $>$. A través de la biblioteca se accede a más de 300 vínculos de recursos temáticos configurados y mantenidos por Miriam Font y Concha de la Torre Calificación: excelente.

- Internet Islamic History Sourcebook < http://www.fordham.edu/halsall/islam/ islamsbook.html $>$. Sección dedicada al Islam y que pertenece al magnífico recurso editado por Paul Halsall dentro del gran proyecto de la Historia en Internet Internet History Sourcebooks. Calificación: excelente.

- Arabismo < http://www.arabismo.com $>$. Portal dedicado al arabismo y a la lengua árabe. Calificación: aceptable.

- Vínculos de Sufismo <http://www.islamyal-andalus.org/Vinculos\%20 de\%20Sufismo.htm $>$. Listado de enlaces relacionados con esta corriente presentada en la web de Yama'a Islámica de Al-Andalus (Liga Morisca). Calificación: excelente.

\section{Bizancio}

- Byzantine \& Medieval Studies Sites <http://www.fordham.edu/halsall/ medweb/>. Sección dedicada a Bizancio y que pertenece al magnífico recurso editado por Paul Halsall dentro del gran proyecto de la Historia en Internet Internet History Sourcebooks. Calificación: excelente.

- Byzantium. Byzantine Studies on the Intenet <http://www.fordham.edu/ halsall/byzantium/> Sitio creado y mantenido también Paul Halsall dentro de su gran proyecto de la Historia en Internet. Calificación: excelente. 


\section{Judíos}

Internet Jewish History Sourcebook < http://www.fordham.edu/halsall/jewish/ jewishsbook.html $>$. Sección dedicada a los judíos y que pertenece al magnífico recurso editado por Paul Halsall dentro del gran proyecto de la Historia en Internet Internet History Sourcebooks. Calificación: excelente.

\section{FUENTES DE INFORMACIÓN DOCUMENTALES}

Uno de los anhelos del investigador es conocer y controlar los documentos procedentes de los archivos históricos junto a la recopilación y lectura de las fuentes narrativas, como libros de viajes, crónicas, diccionarios geográficos, etc. En este apartado tendríamos que añadir los textos de las obras más relevantes de la literatura medieval o los trabajos relacionados con la ciencia, la tecnología y el pensamiento.

El patrimonio documental español es inmenso, tanto los archivos gestionados por las administraciones (Archivo Histórico Nacional, Chancillerías, Archivo General de la Administración, militares, regionales, provinciales y municipales), como los eclesiásticos o los familiares, que disponen de millones de documentos.

Para conocer la procedencia de dichos documentos contamos con dos buenas herramientas, Guías de fuentes documentales de archivos y Censo Guía de Archivos de España e Iberoamérica. La información, en algunos casos, sólo sirve para conocer la existencia de los archivos y, en otros, los inventarios de los fondos. Esta labor es un primer escalón de lo que debería ser un gran avance, que los documentos de archivo puedan consultarse a través de la red. Aunque muy lentamente, esto parece un hecho irreversible. Hoy en día, ya disponemos de algunos recursos para las tres administraciones. Archivos Españoles en Red ya ha volcado 12 millones de originales, el sistema Badator con más de 450.000 registros de documentos de y sobre Euskadi y el Archivo Municipal de Córdoba ha digitalizado 38.000 imágenes de documentos históricos.

El patrimonio bibliográfico comprende un amplio abanico de materias. Un gran bloque es el de la literatura, obras de todos los estilos creadas en todas las regiones. Otro gran conjunto es el de los trabajos relacionados con la ciencia y la tecnología, donde los avances científicos escritos en árabe son los textos más frecuente. Seguidamente, y a caballo con el bloque anterior, aparecen las obras relacionadas con el pensamiento, escritos teóricos, filosóficos, teológicos, etc. Por último, los textos que reflejan los hechos o circunstancias y que fueron redactados por sus testigos o años después, como las crónicas, los libros de viajes, las descripciones de los territorios, etc.

Finalmente, tampoco debemos arrinconar los documentos iconográficos creados en aquella etapa histórica como los mapas y planos y las representaciones pictóricas, etc. Asimismo, aquí deberíamos incorporar las imágenes que 
recogen, generalmente relacionadas con el patrimonio histórico y arqueológico, mueble e inmueble, elementos hoy desparecidos y que pueden reconstruirse mediante, planos, vistas, dibujos, grabados y fotografías antiguas. Este bloque, necesitaría casi de un análisis independiente. Un ejemplo, son los fondos fotográficos del Instituto de Patrimonio Histórico Español, del Departamento de Historia del Arte Diego Velásquez del CSIC y de la Agencia EFE.

Los documentos históricos, tanto los de archivo, como los narrativos, han sido recuperados de las dos maneras posibles: los ejemplares se digitalizan para mostrar la belleza de las páginas miniadas o, simplemente, para permitir su consulta directa; o bien se transcriben los textos, aquí no se busca la plasticidad sino la eficacia. En cada caso encontramos excelentes ejemplos, muestras que transmiten una apreciación objetiva: el patrimonio medieval está disperso por todo el planeta. Curiosamente, si nos dejáramos llevar por la contundencia de las estadísticas, señalaríamos que los mayores y mejores fondos bibliográficos medievales están al otro lado del Atlántico. A la afirmación de que sólo existe aquello que aparece reflejado en Internet, habría que aplicar, que un buen investigador sabe que los mejores fondos están a este lado del océano, estén o no en la red.

Precisamente, son las bibliotecas las organizaciones que deben tomar la iniciativa de digitalizar y colocar en la red las joyas bibliográficas que conservan. Precisamente, son las bibliotecas universitarias norteamericanas las que están a la cabeza en el desarrollo de estas actividades. A continuación, aparecen las británicas y la Biblioteca Nacional de Francia. En este último caso, la intención preferente es la de divulgar el patrimonio cultural francés, una actitud que no tiene su paralelo en la Biblioteca Nacional de España.

Con respecto a la trascripción de textos, la labor recae en los proyectos de investigación o en los portales temáticos. No se excluyen la digitalización facsimilar de transcripciones realizadas hace años, también en esta labor se centran los proyectos y portales, auque cada vez es más frecuentes la entrada de bibliotecas o institutos de investigación de ámbito regional: podemos enumerar varios recursos de gran valor, como el Centro Virtual Miguel de Cervantes o el Centro de Estudios de Castilla-La Mancha, así como los portales temáticos dedicados a Gonzalo de Berceo, a las Cantigas, a la filosofía islámica, a la Celestina, etc.

\subsection{GUÍAS Y CENSOS DE ARCHIVOS}

- Guías de fuentes documentales de archivos < http://www.mcu.es/jsp/ plantillaAncho_wai.jsp?id= 5\&area=archivos $>$. "Los proyectos de las Guías de Fuentes se iniciaron en el año 1984. Se trata de una serie de bases de datos independientes y concatenadas en una sola llamada CIDA. Cada una de ella reúne las referencias descriptivas detalladas de documentos relativos a un mismo tema $y$ 
conservados en diferentes archivos, tanto de España como de otros países».

- Censo Guía de Archivos de España e Iberoamérica <http://aer.mcu.es/sgae/ index_censo_guia.jsp $>$. "Desde el punto de vista de los contenidos, el Censo Guía de Archivos proporciona información de: Los Centros de Archivo, definidos como la institución, unidad administrativa o persona privada encargada de la custodia y servicio de la documentación. Desde este punto de vista, el Censo Guía es un directorio de archivos. Descripción de la documentación que custodia cada centro de archivo, empleando las normas de Descripción Archivística Internacional ISAD-G, a nivel de fondos y colecciones».

\subsection{Documentos de archivos}

- Archivos Españoles en Red (AER) < http://aer.mcu.es/sgae/index_aer.jsp>. La Subdirección General de Archivos, del Ministerio de Educación, Cultura y Deporte, ha creado AER; es decir, ha volcado 12 millones de documentos digitalizados pertenecientes a los archivos estatales.

- Badator < http://www.irargi.org/badator/01doc_badator.htm>. Sistema de Información sobre los Servicios de Archivo y los inventarios de los fondos gestionado por el Centro de Patrimonio Documental de Euskadi (IRARGI), que cuenta con más de 450.000 registros de los documentos pertenecientes a diferentes administraciones como la central, autonómica y municipal, y a los archivos privados.

- Archivo Municipal de Córdoba <http://archivo.ayuncordoba.es/>. El Ayuntamiento de Córdoba ha digitalizado 38.000 imágenes de documentos pertenecientes a las Secciones 1-3 del fondo Archivo Histórico.

\subsection{Textos históricos. Generales}

- EuroDocs: Primary Historical Documents From Western Europe Selected Transcriptions, Facsimiles and Translations < http://www.lib.byu.edu/ rdh/eurodocs/>. No se trata de una institución dedicada a la digitalización o trascripción de textos, sino un catálogo de recursos de sitios que sí realizan esta necesaria tarea. No obstante, al centralizar una serie de recursos, se ha convertido en una buena herramienta para la consulta de documentos relacionados con la Edad Media de la Europa Occidental. Richard Hacken, European Studies Bibliographer, y Harold B. Lee Library, Brigham Young University, Provo, Utah, USA son los responsables de este trabajo, que aparece ordenado por cronología, por áreas regionales y por paises. Para España sería $<$ http://www.lib.byu.edu/ rdh/eurodocs/spain.html $>$.

- Browse images of manuscripts < http://www.bodley.ox.ac.uk/dept/scwmss/ wmss/medieval/browse.htm $>$. En la Bodleian Library de la Universidad de Oxford se cuenta con numeras ilustraciones pertenecientes a manus- 
critos de toda Europa anteriores a 1500. Entre los que se encuentran: los Decretales de Gregorio IX, la Divina comedia de Dante, el Decamerón de Boccacci, etc.

- Early Manuscripts at Oxford University < http://image.ox.ac.uk> Recoge facsímiles digitales completos de 80 manuscritos de esta universidad como La Chanson de Roland.

- Biblioteca de l'Abadia de Montserrat. Biblioteca de Ciènces Humanes i de Teología <http://www.cervantesvirtual.com/portal/Abadia/index.shtml >. Proyecto de digitalización de los mejores fondos emprendido junto a la Biblioteca Virtual Miguel de Cervantes.

- The Berkeley Digital Library SunSITE < http://sunsite.berkeley.edu/>. SunSite está desarrollado por la Universidad de California Berkeley, donde se recogen distintos documentos históricos en varias colecciones?.

\subsection{Fuentes documentales}

\section{Literatura}

- Biblioteca Virtual Joan Lluis Vives < http://www.lluisvives.com/>. Esta Biblioteca Virtual es el fruto del trabajo realizado entre la Universidad de Alicante y el Instituto Juan Lluis Vives y tiene como objetivo forma un catálogo con 500 títulos pertenecientes al patrimonio cultural anterior a 1920. Dentro del catálogo ya han sido incorporados algunos textos de Historia Medieval.

- Gonzalo de Berceo. Obras completas < http://www.geocities.com/urunuela1/ berceo/berceo1.htm $>$. Edición de las obras completas de Gonzalo de Berceo.

9 Catalonian Manuscripts < http://sunsite.berkeley.edu/catalan/>. Dispone de cuatro grupos de ejemplos, los dos primeros correspondiente a textos, como la traducción al catalán de la obra $D e$ consolatione philosophiae, de Boecio, o la Biblia parva. Los otros dos bloques están constituidos por una serie de documentos independientes fechados en 1031-1499 y 1140-1555. De todos ellos se dispone de imágenes digitalizadas. Asimismo, cuando existe, cada grupo está apoyado con un excelente estudio bibliográfico. The Digital Scriptorum < http://sunsite.berkeley.edu/Scriptorium/> . Digital Scriptorum pretende crear una base de datos con el catálogo de manuscritos medievales y del Renacimiento pertenecientes a varias instituciones, en concreto de la Biblioteca Bancroft (UC Berkeley) y de la sala Rare Book and Manuscript Library of Columbia. El material digitalizado se contabiliza en 700 códices y 2.000 documentos correspondientes a los siglos VIII-XV. La base de datos permite buscar los documentos con distintos formularios, como la localización topográfica, por la región de procedencia o la data y por autor, título o término en el texto. Como resultado de la búsqueda obtendremos una ficha completa con los datos del documento, junto a la imagen digitalizada. The Online Medieval and Classical Library (OMACL) < http://sunsite.berkeley.edu/OMACL/>. Douglas B. Killings es el responsable de un proyecto que tiene por objeto recopilar los trabajos literarios más importantes del mundo clásico y medieval. Además de contar con un motor de búsqueda, los textos han sido ordenados por título, autor, género y lengua. 
- The Cantigas de Santa Maria <http://www.pbm.com/ lindahl/cantigas/>. Además de recopilar una serie de enlaces relacionados con la obra y con Alfonso X, añade un apartado dedicado a la discografía, dispone de imágenes digitalizadas de los manuscritos en distintos formatos de la edición que preparó en su día Julián Ribera ${ }^{10}$. Cuestión aparte es la digitalización de las zonas iluminadas, con dos opciones, una que recupera el facsímil y otra que recupera la digitalización en color.

\section{Pensamiento}

- Història Medieval < http://www.ricardocosta.com/>. Página personal de la profesor Ricardo da Costa, de la Universidad Federal do Espírito Santo (UFES) de Brasil y especializado en la figura de Ramon Llull. Dispone de textos de filosofía, entre los que se encuentra el propio Llull. Textos en portugués.

- The digital documentation center (DDC) <http://ddc.aub.edu.lb/>. DDC de la Universidad Americana de Beirut, entre otros proyectos están digitalizando documentos históricos: Edición, de 1593, de Canon de Medicina de Avicena; Majmu'ah de 1093; Taabeer al-Manamat de Ibrahim bin Yahya bin Gannan al-Maqdisi, sobre la interpretación de los sueños y cuya cronología es del siglo XIV. También ofrece distinta información relacionada con las actividades arqueológicas realizadas en el área BEU006 o la digitalización de algunos números sueltos de la revista Beytus, cuya andadura comenzaría en 1934.

\section{Libros de Viajes}

- Liber Sancti Jacobi «Codex Calixtinus» < http://personal.readysoft.es/oborras/ csantiago/codex.htm $>$. El códice escrito por Aymeric Picaud, está siendo traducido al castellano por los profesores A. Moralejo, C.Torres y J. Feo. No está todo el texto completo, aún falta el libro I.

\section{Historia de la Iglesia}

- Guide to Early Church Documents < http://www.iclnet.org/pub/resources/ christian-history.html\#later $>$. Textos históricos relacionados con la historia de la Iglesia. Lengua inglesa.

\subsection{Regiones}

- Textos y documentos de Historia Medieval de España $<$ http://fyl.unizar.es/Medieval/Text_Mediev.html>. Selección de textos

10 RiBERA, Julián (edic.): La Música de Las Cantigas. Estudio sobre su origen y naturaleza con reproducciones fotográficas del texto y trascripción moderna, Madrid, Tipografía de la Revista de Archivos, 1889-1922. 
relacionados con la Historia Medieval de España, que se aportan como material docente del Departamento de Historia Medieval de la Universidad de Zaragoza.

- Documentación Virtual del Centro de Estudios de Castilla-La Mancha $<$ http://www.uclm.es/ceclm/virtual/index.htm>. Esta institución, dependiente de la Universidad de Castilla-La Mancha, durante los últimos años ha recuperado una serie de publicaciones locales y regionales de gran valor. Además, de un conjunto de revistas, disponemos de una excelente representación de textos de investigación y de fuentes, como las Relaciones topográficas ${ }^{11}$, diccionarios histórico-geográficos, catálogos monumentales ${ }^{12}$, etc $^{13}$.

\subsection{Cartografía}

- Cartographic Images. En esta web podemos encontrar dos bloques de ejemplos de la cartografía medieval: El primero, Early medieval maps, 400 a.d.-1300 a.d. < http://www.henry-davis.com/MAPS/EMwebpages/EM1.html>, que ha recopilado 195 ejemplos, la mayoría digitalizados. El segundo, Late Medieval Maps 1300-1500 <http://www.henry-davis.com/MAPS/ LMwebpages/LM1.html>, con 264 documentos recopilados. En ambos casos, se acompaña de una pequeña bibliografía.

\section{OBRAS DE REFERENCIA}

Las obras de referencia no se consideran documentos primarios, aunque en algunos momentos su consulta se hace prioritaria. Los catálogos automatizados de las bibliotecas, las bases de datos bibliográficos y las bibliografías reflejan fielmente esta afirmación. También, son los diccionarios lingüísticos, los traductores, las enciclopedias, directorios, etc., recursos de uso generalizado para cualquier área de conocimiento. Con respecto a la Edad Media, no hay mucho donde elegir, como la colección de mapas de la Biblioteca Perri-Castañeda o el Liber Monstrorum con las representaciones iconográficas del bestiario medieval.

Uno de los modelos de obra de referencia que tendría que generalizarse como recurso de gran utilidad es Philosophy of History una de las páginas incluidas

11 Ortiz García, Antonio, ed.: Relaciones topográficas de Felipe II de la provincia de Guadalajara. VIÑAs MEY, Carmelo y PAZ, Ramón: Relaciones histórico-geográfico-estadísticas de los pueblos de España hechas por iniciativa de Felipe II: Ciudad Real, Madrid, 1971. Relaciones histórico-geográfico-estadísticas de los pueblos de España hechas por iniciativa de Felipe II: Reino de Toledo, Madrid, 1951.

12 PORTUONDO, Bernardo: Catalogo monumental artístico de España: provincia de Ciudad Real, Madrid, 1917.

13 García SÁinz de Baranda, Julián y Cordavias, Luis: Guía Arqueológica y de Turismo de la provincia de Guadalajara, Guadalajara, [s.n.], 1929. 
dentro de la web The Proceedings of the Friesian School, Fourth. La cronología, por su estructura de enlaces cruzados a temas, lugares, personajes, etc. hay que considerarla como una verdadera enciclopedia de la historia de la Filosofía universal.

\subsection{Atlas}

- Holl, Rinehart and Winston <http://go.hrw.com/atlas/norm_htm/world. htm $>$. Cartografía del mundo actual. Recuperación de mapas por continentes y países. Textos en castellano y en inglés.

- Perry-Castañeda Library Map Collection <http://www.lib.utexas.edu/ maps $/>$. Dispone de mapas de todo el mundo. Aparecen organizados por continentes, por áreas y por países. La mayoría son de cronología actual o reciente, aunque también dispone de mapas históricos. Con respecto a este último caso se informa de la procedencia del original digitalizado.

- Europe antiques cartographies < http://www.euratlas.net/cartogra/>. Este sitio suizo facilita una serie de mapas de Europa que recoge la situación del continente cada cien años desde el año primero de nuestra era hasta el tercer milenio.

\subsection{Cronologías}

- Philosopby of History <http://www.friesian.com/philhist.htm >. Dentro de la magnífica web The Proceedings of the Friesian School, Fourth Series disponemos de una cronología universal que recoge toda las edades, desde la evolución humana. Aparece en formato enciclopédico, sobre todo en lo que se refiere a la disponibilidad de tablas, árboles genealógicos de los gobernantes, mapas, etc. Además, facilita la tarea para saltar de un ámbito geográfico a otro, o de un término a otro, mediante referencias cruzadas. Desde el punto de vista español dispone de un apartado para los reinos de España y Portugal <http://www.friesian.com/perifran.htm\#spain > y otro para Al-Andalus <http://www.friesian.com/islam.htm\#spain $>$. Textos en inglés

- Ibercronox: Cronologías de España, Portugal y Andorra < http://www. geocities.com/Athens/Atlantis/2572/ $>$. Listado de reyes desde el Reino Visigodo hasta el Reino de Navarra. Incluye los reinos taifas.

- Esbozo de la Edad Media Española <http://www.humnet.ucla.edu/santiago/ timeline.html $>$. Cronología resumida, escrita por John Adueñáis del Dept. of Spanish and Portuguese, University of California, que recoge los acontecimientos más destacados de la época. 


\subsection{DICCIONARIOS Y ENCICLOPEDIAS}

- Liber Monstrorum <http://es.geocities.com/quinapor/liber_monstrorum. htm >. Catálogo confeccionado por Anna Ribot i Urbita que recopila en formato enciclopédico iconografía y descripciones del bestiario medieval.

- L'Encyclopédie Médiévale <http://www.medievalenfrance.com/>. Enciclopedia creada por Pascual Bacro destinada al mundo medieval y su literatura.

- Diccionario de Arte Románico <http://www.santamarialareal.org/diccio. htm >. Diccionario de términos del arte románico confeccionado por la Fundación Santa Maria la Real de Aguilar de Campoo (Palencia), con dos versiones: una de texto y otra con imágenes y gráficos que mejoran la compresión de las definiciones.

\section{LAS BIBLIOGRAFÍAS}

Al hablar de las obras de referencia ya se citaban los catálogos automatizados de las bibliotecas, las bases de datos bibliográficas y las bibliografías. Los dos primeros formatos cumplen el objetivo de proveer de títulos bibliográficos al investigador desde una doble vertiente; primero en cuanto a la verificación de la existencia de los trabajos y su localización física en los fondos de las bibliotecas; y, segundo, la actualización de los listado con la incorporación de las publicaciones recientes.

Con respecto a los catálogos y bases de datos bibliográficas hay que hacer una advertencia, siempre que se haga una consulta debemos saber la cobertura real de los productos. No siempre existe una relación directa entre el catálogo automatizado y el fondo real de las bibliotecas. El mejor ejemplo es la Biblioteca Nacional de España. A pesar de contar con ejemplares de todas las épocas y de ser el Depósito Legal, el catálogo ARIADNA dispone de algo más de 2.5 millones de registro, mientras que la cifra real de sus fondos se aproxima a los $10 \mathrm{mi}-$ llones de ejemplares de todo tipo; por lo que cada vez que consultemos el catálogo, siempre tendremos que hacer una doble tarea, la automática y la manual.

El tercer formato, permite la especialización temática, con la agrupación de monografías, artículos, capítulos y aportaciones en actas que tratan un aspecto de la historia, labor que los catálogos y la mayoría de las bases de datos bibliográficas no atienden. No obstante, las ventajas de las bibliografías quedan anuladas casi inmediato al no actualizarse con las nuevas referencias que aparecen cada mes.

Las tecnologías de la información han puesto en manos de los expertos una gran herramienta: la base de datos. Las bibliografías confeccionadas, no como listados, sino como base de datos, permiten la actualización periódica de los contenidos. Sin embargo, hoy en día, al valorarse más las ediciones en papel que las electrónicas, se siguen editando en ese formato. 
Los catálogos automatizados de referencia son los pertenecientes a los fondos de las tres grandes bibliotecas nacionales europeas, las de España, Francia y Gran Bretaña, a las que habría que sumar la Biblioteca del Congreso de Estados Unidos. Además, estableciendo una cadena de explotación de los todos los fondos bibliográficos con el fin de completar la bibliografía sobre el tema de nuestro interés y localizar los ejemplares, tendríamos que acudir a la red de bibliotecas del CSIC, a las bibliotecas universitarias y, en último caso, a la red de bibliotecas publicas del Estado. Asimismo, para estar al tanto de lo que se publica, además de los catálogos de las editoriales y librerías especializadas, deberíamos consultar la base de datos del ISBN o la de Tesis Doctorales Teseo. Nuestra retrospectiva estaría incompleta al excluir otras opciones, como las que ofertan las bibliotecas especializadas, en este caso las del Museo Arqueológico Nacional y AECI, y las regionales de Castilla-León, Madrid, Castilla-La Mancha — biblioteca regional y el CECLM - o Cataluña. Con respecto a este último caso, el catálogo colectivo incluye los fondos del Museo Nacional de Arte de Cataluña, con una importante colección de pintura románica.

Hasta aquí la tarea es sencilla. La complejidad en la búsqueda de las fuentes de información bibliográfica se centraliza en conocer la investigación publicada en las revistas científicas, profesionales o de divulgación y en las actas, amen de los capítulos de los libros colectivos. Los catálogos de las bibliotecas no recogen este material, por lo que debemos acudir a otros recursos. Estamos hablando de las bases de datos de revistas o de los sumarios. En este aspecto el rastreo ofrece magnificas posibilidades, sobre todo al contar con el CINDOC, o Centro de Información y Documentación Científicas dependiente del CSIC. Uno de sus institutos, el ISOC ha creado un extraordinario producto las Bases de datos ISOC, que recoge los artículos de las revistas científicas españolas desde 1976. Como complemento a estas bases de datos disponemos de Compludoc, un producto de la Universidad Complutense, para algunos la mejor. Esto es un error de apreciación, pues cuando uno navega por Internet valora exclusivamente aquello que puede consultar. Para poder trabajar dentro del ISOC es necesario la suscripción previo pago, por lo que para la mayoría no existe.

Un recurso intermedio de gran valor estratégico para el investigador, sobre todo para que nuestro conocimiento esté siempre al día, es Dialnet, servicio de alerta documental de publicaciones periódicas creado por la Universidad de La Rioja.

No obstante, el atajo correcto en la recopilación de los trabajos de investigación está en las bases de datos bibliográficas generales de la Edad Media. La más representativa es la correspondiente con el Repertorio de medievalismo hispánico, obra iniciada por Emilio Sáez en formato papel, y continuada por el Departamento de Estudios Medievales de la Institució Milà i Fontanals. Esta labor, tan complicada y lenta, mejoraría aún más si dispusiésemos de bibliografías especializadas, casi siempre es la respuesta de una investigación escrupulosa y metódica, que lleva al historiador a recopilar casi todo lo publicado sobre un tema hasta la fecha de finalización de la edición. Hoy en día disponemos de 
buenos ejemplos publicados en libros y artículos, pero bastantes menos en formato electrónico. Los originales que adoptan la formula de la base de datos aún es un bien escaso.

Las más interesantes de las aquí representadas son las bibliografías sobre las Ciencias Auxiliares de la Historia, la de Historia de la Ciencia, Feminae, Arthuriana o sobre las Ordenes Militares peninsulares.

\subsection{Bibliotecas generales}

- Catálogo Ariadna de la Biblioteca Nacional de Madrid <http://www.bne.es/ esp/cat-fra.htm $>$. De las diferentes salas interesan: la Sala General, donde consultan las monografías que se conservan en el Depósito General; la Sala Cervantes, por ejemplo, incluye 2.000 códices medievales; o la Sala de Publicaciones Periódicas, con aproximadamente 400 títulos. Es necesario advertir, que el catálogo bibliográfico no recoge todo el fondo del que dispone la Biblioteca, por lo que será necesario consultar también el catálogo manual. Igualmente en preciso tener en cuenta el Catálogo Colectivo de Publicaciones Periódicas.

- Junto a la Biblioteca Virtual Miguel de Cervantes se ha creado un portal denominado, Clásicos en la Biblioteca Nacional <http://www. cervantesvirtual.com/portal/BNE/ $>$, destinado digitalizar las ediciones singulares de los autores españoles más importantes.

- Catálogos de las Bibliotecas Públicas del Estado (BPE) < http://www.mcu.es/ bpe/bpe.html>. Recoge los fondos bibliográficos de la Bibliotecas Públicas del Estado, Bibliotecas Centrales de Comunidades Autónomas y Servicios Autonómicos que forman parte de la Red de Bibliotecas Públicas.

- Bibliotecas universitarias y de investigación españolas <http://www.csic.es/ cbic/webuni.htm $>$. Acceso directo a las bibliotecas universitarias ordenadas por comunidades autónomas. Asimismo, también se encuentran los siguientes enlaces: Rebium (Red de Bibliotecas Universitarias), los consorcios de bibliotecas universitarias de Cataluña, Galicia y Madrid; este último tiene incorporada a la UNED.

- Catálogo Colectivo de la Red de Bibliotecas del CSIC < http://www.csic.es/ cbic/cbic.htm $>$. Entre otras colecciones se encuentra la Biblioteca del Instituto de Historia.

- Catálogo de la British Library <http://www.bl.uk/catalogues/ toppage. html >. Entre las colecciones reseñamos The British Library Public, Manuscritos, Mapas, Publicaciones Periódicas. En cada momento indican desde que año los ejemplares están operativos dentro de los distintos catálogos automatizados. Destaca los ejemplares digitalizados de manuscritos medievales y renacentistas <http://prodigi.bl.uk/illcat/welcome.htm $>$.

- Catálogo de la Biblioteca Nacional de Francia < http://www.bnf.fr/pages/ 
zNavigat/frame/catalog.htm >. Libros, Publicaciones Periódicas, Manuscritos, etc. Destaca el catálogo de publicaciones periódicas electrónicas $<$ http://www.bnf.fr/pages/catalog/perelec/index.html>; así como alguna de las exposiciones virtuales, como: Gastronomía medieval; Geografía de Idrisi; El arte del libro árabe; Splendeurs persanes Le roi Charles $V$ et son temps (1338-1380); Naissance de la Culture Française: Trésors de la Bibliothèque nationale de France

- Catálogo The Library of Congress <http://catalog.loc.gov/>. Además de los catálogos comunes, dispone de índice de numerosos sitos web temáticos creados por la propia Biblioteca.

\subsection{Bases de datos bibliográficas generales}

- Agencia Española del ISBN <http://www.mcu.es/bases/spa/isbn/ISBN.html>. La base de datos recoge los libros editados en España desde 1972 y que disponen del ISBN.

- Teseo <http://www.mcu.es/TESEO/index.html>. La base de datos Teseo recoge las Tesis Doctorales leídas en España y calificadas aptas desde 1976. A pesar del completo formulario para buscar una Tesis, la recuperación del documento deseado es complicado.

\subsection{Bibliotecas de historia y de patrimonio histórico}

- Museo Arqueologico Nacional <http://www.mcu.es/bases/spa/cbma/>. «Este catálogo incluye todas las obras que han ingresado en la Biblioteca desde el 1 de Septiembre de 1998, y los registros bibliográficos que proceden del Proyecto Eneas (Reconversión de los catálogos manuales). No están todos los libros que forman la colección».

- Servicio de Documentación del Instituto del Patrimonio Histórico Español < http://www.mcu.es/bases/spa/bphe/BPHE.html>. El catálogo automatizado de los fondos bibliográficos este instituto, actualmente, contiene más de 21.000 registros.

- BEG. Biblioteques Especialitzades de la Generalitat < http://beg.gencat. net/ $>$. Dentro de la BEG se encuentra el catálogo automatizado del CIIPAC, Centre d'Informació i Investigació del Patrimoni ArtiscCIIPAC.

- Bibliotecas Hispánica e Islámica de la AECI <http://www.aeci.es/ sirtexweb1.html>. Estas dos bibliotecas reúnen medio millón de volúmenes, libros y revistas incluidos; aunque es la segunda, creada en 1954, la que ofrece la mejor alternativa para la investigación referida al mundo islámico. 
- Biblioteca de la Escuela de Estudios Árabes. CSIC < http://www.csic.es/ cbic/eara/ara2.htm $>$. El catálogo de la Biblioteca de la Escuela de Estudios Árabes, ubicada en La Casa de Chapiz en Granada, está integrada en la Red de Bibliotecas del CSIC < http://www.csic.es/cbic/cbic.htm>.

- Real Biblioteca <http://realbiblioteca.patrimonionacional.es/>. Catálogo automatizado incompleto de los fondos (manuscritos, libros, cartografía, dibujos y grabados, fotografías, etc.) pertenecientes a la biblioteca Real Particular o de Cámara, que sirvió como biblioteca privada a los reyes de la Casa de Borbón desde la llegada de Felipe V.

- El Catálogo Colectivo del Patrimonio Bibliográfico <http://www.mcu.es/ $\mathrm{ccpb} /$ index.html $>$. El «Catálogo Colectivo tiene como objetivo el inventario y la descripción del Patrimonio Bibliográfico depositado en bibliotecas españolas, públicas o privadas». El catálogo «contiene 580.821 registros que describen en su mayor parte distintas ediciones de obras impresas entre los siglos XV y XX, así como información sobre 1.323.946 ejemplares concretos de dichas ediciones depositados en cerca de 625 bibliotecas». El catálogo está elaborado conjuntamente por el Ministerio de Educación, Cultura y Deporte y las Comunidades Autónomas.

\subsection{Biliotecas regionales. Castilla-La Mancha. Castilla y León Cata- luña. País Vasco}

- Biblioteca de Castilla y León <http://www.bcl.jcyl.es/>. Además del catálogo de la Biblioteca dispone de varias bibliografías: Bibliografía de Castilla y León, bibliografía regional que se corresponde con los materiales de Depósito Legal (1982) < http://www.bcl.jcyl.es/BibliografiaCyL/>; Bibliografías locales < http://www.bcl.jcyl.es/BiblioLocales/>, una para $\mathrm{Pa}-$ lencia, preparada por la Institución «Tello Tellez de Meneses», y otra para Salamanca, Elaborada por la Fundación Sánchez Ruipérez.

- Biblioteca de Castilla-La Macha <http://www.jccm.es/biblioclm/>.

- Centro de Estudios de Castilla-La Mancha (CECLM) < http://www.uclm.es/ ceclm/indexr.htm > . Organismo dependiente de la Universidad de CastillaLa Mancha, tiene su sede en Ciudad Real. El CECLM dispone de varias bases de datos <http://www.uclm.es/ceclm/bases.htm\#bibliografia $>$. La primera de ellas el Catálogo que recoge los documentos que se encuentran físicamente en el Centro; la segunda, Bibliografía Regional, que recoge el vaciado de revistas, publicaciones colectivas y las citas de las tesis doctorales; y la tercera, Documentación Virtual, contiene los documentos reproducidos digitalmente.

- Biblioteca Nacional de Cataluña <http://www.gencat.es/bc/>. La Biblioteca de Cataluña dispone de varios catálogos a tener en cuenta: el Catàleg Col-lectiu del Patrimoni Bibliogràfic de Catalunya <http://www.gencat.es/ bc/4_catale/set4_1.htm> y el Catàleg Collectiu de Catalunya <http:// 
www11.gencat.es/plugin502.nd/mvc/bc $>$ donde se integran, además de los pertenecientes a la propia Biblioteca y el Patrimonio Bibliográficos, los fondos del Museo Nacional de Arte de Cataluña y varias bibliotecas públicas provinciales.

- Biblioteca de la Fundación Sancho el Sabio < http://www.fsanchosabio.es/menu.htm $>$. Dependiente de la Institución Sancho el Sabio de Álava, cuenta con el catálogo con su producción bibliográfica, así como otros formatos relacionados con la cultura vasca; manuscritos desde el siglo XV y material cartográfico desde el XVI.

\subsection{Bases de datos generales de artículos de revistas}

- Bases de datos del CINDOC (Centro de Información y Documentación Científica) < http://www.cindoc.csic.es/>. El ISOC publica por primera vez, en 1976, el Índice Español de Humanidades y el Índice Español de Ciencias Sociales. Estos índices recogen, «en forma de referencia bibliográfica y en sus respectivas áreas, los artículos publicados en las revistas científicas españolas». El acceso a las bases de datos se realiza previo pago, aunque es posible recuperar los contenidos utilizando los sumarios de las revistas $<$ http://bddoc.csic.es:8080/>.

- Compludoc <http://www.ucm.es/BUCM/complu/frame.htm>. "Contiene las reseñas de los artículos publicados en una selección de más de mil revistas científicas, en su mayoría españolas, analizadas en la Biblioteca de la Universidad Complutense». La cobertura se remonta a 1997. A parte de los datos de referencia de cada artículo, incorpora un breve resumen. Además, se facilita el sumario de las revistas correspondientes a los últimos seis meses, junto al listado completo, ordenado por orden alfabético en combinación con las facultades, de las revistas analizadas.

- DIALNET < http://dialnet.unirioja.es/index.jsp > Servicio de alerta documental que «permite estar al día de la producción científica en lengua española». Igualmente, sirve para recuperar los sumarios de un número elevado de revistas de interés, que no sería posible por otro medio.

\subsection{Bases de datos bibliográficas generales de edad media}

- Repertorio de medievalismo bispánico < http://www.imf.csic.es/Medievales/ Repertorio/cerca.htm $>$. Base de datos creada y gestionada por el Departamento de Estudios Medievales de la Institució Milà i Fontanals del CSIC. "Recoge la labor científica de los estudiosos españoles y portugueses y de los investigadores hispanistas y lusistas sobre temas bispánico-medievales (4001525)». El material inicial se corresponde con los trabajos desarrollados 
por Emilio Sáez ${ }^{14}$, publicado en cuatro volúmenes, correspondientes a los años 1955-1975/1985. La base de datos gestiona actualmente más de 70.000 registros.

- The International Medieval Bibliography <http://www.leeds.ac.uk/ims/ $\mathrm{imb} /$ index.html > fue creada en 1967 por la Medieval Academy of America, con el objetivo de recoger las aportaciones publicadas en revistas y publicaciones misceláneas editadas en todo el mundo. El International Medieval Institute, University of Leeds, es el responsable de la gestión que coordina el trabajo de equipos de especialistas que se encarga de recoger regularmente toda la producción. Actualmente, la base de datos cuenta con 300.000 registros clasificados por fecha, tema y lugar.

- Iter. Gateway to the Middle Ages and Renaissance <http://www.itergateway. org $/>^{15}$. Esta base de datos recoge los artículos publicados en revistas, que analizan de manera iterdisciplinar la etapa cronológica comprendida entre los años 400 y 1700. Para orientar a los usuarios se facilita el listado de más de 1.100 de las revistas analizadas. Es necesario la suscripción.

\subsection{Bases de datos bibliográficas sobre fuentes de información. Ar- chivos. Textos}

- Bibliografía de archivos <http://www.cultura.mecd.es/archivos/jsp/ plantillaAncho.jsp? id=6>. "Catálogo que recoge todas las publicaciones de la biblioteca del CIDA [de la Subdirección General de Archivos del Ministerio de Educación, Cultura y Deporte], así como los artículos de revistas y de publicaciones misceláneas que suponen la mitad de los registros. Cuenta con unos 35.000 registros, de los que alrededor de 9.000 corresponden a censos, guías, catálogos e inventarios de todos los archivos españoles, así como de los principales archivos extranjeros. Destaca la información detallada que proporciona del contenido y tipología de cada publicación a través de materias y descriptores. Se inició en 1978 y se actualiza regularmente».

14 SÁEZ, Emilio y Rossell, Mercé: Repertorio de medievalismo hispánico: (1955-1975), Barcelona, El Albir, 1976.

15 BeGHTOL, Clare: «The Iter Bibliography: International Standard Subject Access to Medieval and Renaissance Materials (400-1700)», [en línea], <http://www.itergateway.org/ifla.htm>, [consulta: 3110-2003]. Bowen, William R.: «Iter: Where Does the Path Lead?», Early Modern Literary Studies, 5, 3, Special Issue 4, (2000), [en línea], < http://purl.oclc.org/emls/05-3/bowiter.html > y <http://www.nlcbnc.ca/eppp-archive/100/201/300/early_modern/html/2000/05-3/bowiter.html >, [consulta: 3110-2003]. CASTELL, Tracy: «Maintaining Web-based Bibliographies: a Case Study of Iter, the Bibliography of Renaissance Europe», American Society for Information Science 97: Digital Collections: Implications for Users, Funders, Developers and Maintainers, Washington, 1997, [en línea,] < http:// www.asis.org/annual-97/castell.htm>, [consulta: 31-10-2003]. 
- PhiloBiblon <http://sunsite.berkeley.edu/PhiloBiblon/phhm.html>. PhiloBiblon es una base de datos bio-bibliográfica de textos creados en la Península Ibérica. Se trata de un producto sorprendente, pues aparentemente es un conjunto constituido por tres bibliografías independientes que aparecen, en bloque y por separado, identificadas como publicación seriada $^{16}$.

4.8. Bases de datos bibliográficas especializadas. Historia de la Ciencia. Historia de las mujeres. Siglo XV español. Lírica profana. Ramon Llul

- Bibliografía española de Historia de la Ciencia y de la Técnica <http:// 161.111.141.93/hcien/default.htm >. El objeto de esta base de datos es recopilar la totalidad de publicaciones sobre historia de la ciencia editadas en España a partir de 1988. El producto, dirigido por María Luz López Terradas, pertenece al «Instituto de Historia de la Ciencia y Documentación López Piñero» de Valencia, un centro mixto del CSIC y de la Universidad de Valencia. Al día de hoy, cuenta con casi 13.000 registros bibliográficos.

- Feminae: Medieval women and Genter Index <http://www.haverford.edu/ library/reference/mschaus/mfi $/ \mathrm{mfi} . h t m>$. Esta base de datos recoge los artículos publicados entre 1992 y nuestros días, extraídos de 450 revistas. En total son 8.000 registros que abarcan trabajos monográficos relativos a las mujeres durante la Edad Media (450-1500).

- Centro de documentación Juan Alfonso Baena <http://www. juanalfonsodebaena.org $>$. Base de datos que recoge la colección de este centro dedicado a los estudios del siglo XV, y en particular del cancionero.

- Base de datos de lírica profana galego-portuguesa <http://airas.cirp.es/ WXN/wxn/homes/meddb.html >. Base de datos dedicada a los estudios de literatura medieval, en particular a la lírica profana gallegoportuguesa. «MedDB é unha base de datos que contén o corpus completo das cantigas medievais dos trobadores galego-portugueses, acompañado de información detallada tanto das composicións coma dos aspectos histórico-biográficos dos trobadores» ${ }^{17}$. La MedDB es de libre uso, pero

16 Faulhaber, Charles B., Gómez Moreno, Ángel, Moll Dexeus, Ángela y Cortijo OCAÑA, Antonio: «BETA.Bibliografía Española de Textos Antiguos», PhiloBiblon, 2, (2002), $<$ http://sunsite.berkeley.edu/PhiloBiblon/phhmbe.html>. Versión en castellano. Askins, Arthur L-F., Sharrer, Harvey L., DiAS, Aida Fernanda y ShAfFer, Marhta E.: «BITAGAP. Bibliografia de Textos Antigos Galegos e Portugueses», PhiloBiblon, 2, (2003), <http://sunsite.berkeley.edu/ PhiloBiblon/phhmbp.html>. Versión en gallego y portugués. BeLtrán, Vicenç, AvenOZA, Gemma y CONCHEFF, Beatrice: «BITECA. Bibliografia de Textos Catalans Antics», 2, (2003), $<$ http://sunsite.berkeley.edu/PhiloBiblon/phhmbi.html $>$. Versión en catalán

17 BREA, Mercedes (dir.): MedDB Especificacións: Base de Datos da Lirica Profana Galego-Portuguesa. MedDB 1.0, [en línea], <http://airas.cirp.es/WXN/wxn/frames/meddb.html>, [consulta: 5-11-2003]. 
requiere suscripción previa. La base de datos, cuyos trabajos están dirigidos por Mercedes Brea, depende del Centro Ramón Piñeiro para la Investigación en Humanidades.

- Base de Dades Ramon Llull - Llull DB < http://orbita.bib.ub.es/llull/>. La base de datos está dedicada a recopilar toda la información disponible sobre Ramon Llull. Creada por Anthony Bonner y desarrollada por el Departamento de Filología Catalana y por la Biblioteca de la Universitat de Barcelona, dispone de cuatro bloques de documentos: obras, bibliografía, manuscritos, catálogos e inventarios. Acompaña al producto, como valor añadido, una serie de textos complementarios que ayudan a entender, la figura, la obra y la época; así como, varios listados bibliográficos, uno para el renacimiento, otro sobre Giordano Bruno y, el tercero, una gran parte de los números perteneciente al boletín Bibliografía de Studia Lulliana.

\subsection{Bibliografías}

- Ménestrel. Médiévistes sur l'internet sources travaux références en ligne $<$ http://www.ccr.jussieu.fr/urfist/menestrel/medbd.htm>. Dentro del catálogo general dispone de un directorio de Bibliografías.

\section{Bibliografías temáticas. Saga Artúrica. Carolingios.}

- Arthuriana. Camelot Projet Bibliographies <http://www.lib.rochester.edu/ camelot/acpbibs/bibhome.stm>. Auspiciado por la web Arthuriana el Proyecto Camelot tiene entre sus objetivos desarrollar trabajos bibliográficos dedicados a los temas artúricos.

- The Carolingians. An english-language bibliography <http://www.wmich.edu/ medieval/research/rawl/carolingian/ $>$. Bibliografía creada por Thomas F. X. Noble y Julia M. H. Smith del Department of History University of Virginia en el año 1997.

Bibliografías temáticas. Historia del Derecho Español. Órdenes Militares. Camino de Santiago. Gonzalo de Berceo. Hagiografía medieval. Alandalus. Serfarad

- Bibliografía histórico-jurídica en los últimos 25 años. Un Balance de 25 años de historigrafía-jurídica en España (1973-1998) < http://www.ucm.es/info/ byblos/bibpuyof.htm $>$. Artículo publicado, primero en Cuadernos de Historia del Derecho, V, 1998, pp. 283-409 y, ahora, en BYBLOS Revista de Bibliografía Histórico-Jurídica, por José María Puyol Montero. Los capítulos que nos interesan son los siguientes: «La expansión y vulgarización del Derecho Romano: la España Visigoda», «La Pervivencia y crisis de la tradición ju- 
rídica romana (Siglos VIII-XIII)» y «La recepción y triunfo del Ius Commune en la Península (siglos XIII-XVII)». No obstante, es necesario advertir que, lógicamente, comienza a acusar cierto desfase por la no actualización para los últimos años.

- El camino de Santiago <http://www.bibliotecajacobea.org/contenidos. html >. Bibliografía diversa sobre el Camino de Santiago y las peregrinaciones preparada por la Biblioteca Jacobea del Camino de Santiago, del Centro de Estudios y Documentación del Camino de Santiago, ubicada en la localidad palentina de Carrión de los Condes.

- Military Orders in the Iberian Peninsula-Bibliography <http://www.geocities. $\mathrm{com} /$ josev.arnoso/militaryorders/biblioindex.htm>. Bibliografía de las Ordenes Militares peninsulares, organizada por varios temas, que está ubicada dentro de una web dedicada a las Órdenes Militares Portuguesas (The Portuguese Military Orders), creada y mantenida por José Vicente de Bragança.

- Bibliografía de Gonzalo de Berceo <http://web.uniovi.es/CEHC/bibberceo. htm > . Bibliografía creada por Isabel Uria Maqua y Fernando Baños Vallejo ${ }^{18}$, y actualizada por Vanesa Hernández Amez.

- Bibliografía electrónica del libro: Andalusíes. La memoria custodiada <http:// www.eea.csic.es/Divulgacion/Andalusies/portada.htm $>$. Recopilada y organizada en seis secciones por Juan Castilla Brazales.

- Sefarad Bibliography <bttp://wuww.lib.utexas.edu/subject/iberian/Sefarbiblio.html>. Bibliografía general para Sefarad organizada por orden alfabético y confeccionada dentro del Proyecto Sefarad de la Universidad de Texas a través de la Biblioteca Perry-Castañeda.

\section{Bibliografías regionales. España. Aragón. Cataluña}

- Bibliografía de Historia Medieval de España < http://fyl.unizar.es/Medieval/ Bib_Mediev.html $>$. Breve bibliografía preparada por el Departamento de Historia Medieval, Ciencias y Técnicas Historiográficas y Estudios Árabes e Islámicos Universidad de Zaragoza que se incluye dentro de los materiales preparados para la docencia.

- Bibliography for the History of Medieval Catalonia <http://www.columbia. edu/ ajk44/catbib/index.html $>$. Bibliografía de Cataluña preparada por Paul Freedman y Adam J. Kosto.

- Bibliografía de Aragón en la Edad Media <http://fyl.unizar.es/Medieval/ Bib_Aragon.html>. Bibliografía recopilada por el Departamento de Historia Medieval, Ciencias y Técnicas Historiográficas y Estudios Árabes e Islámicos de la Universidad de Zaragoza que se incluye dentro de los materiales preparados para la docencia.

18 URía MAQUA, Isabel y BaÑos VALLerJo, Fernando: «Bibliografía de Gonzalo de Berceo», Boletín Bibliográfico de la Asociación Hispánica de Literatura Medieval, 10 (1996), pp. 269-338. 


\section{Bibliografía de Ciencias Auxiliares. Paleografía. Diplomática. Archivísti- ca. Museología.}

- Gestión Documental Automatizada del Patrimonio Histórico <http://patrimoniohistorico.unex.es $>$. El Departamento de Ciencias y Técnicas Historiográficas de la Universidad de Extremadura ha creado una página web destinada a las prácticas de las distintas asignaturas que imparte.

\section{HEMEROTECA}

El formato electrónico ha subrayado la capacidad de comunicación de las publicaciones periódicas, en especial de las revistas, por diferentes motivos como: por la inmediatez en la distribución de cada número, lo que permitiría mantener la frescura de los artículos; posibilidad de incluir documentos multimedia (imágenes, sonidos, vídeos, gráficas interactivos, etc.); en el caso de disponer de referencias de recurso electrónicos en línea, tendremos la posibilidad de consultar la fuente primaria de manera inmediata; mediante los buscadores, podremos localizar un término o un tema de manera puntual; posibilidad de reproducción del documento en cualquier momento; al mismo tiempo puede abarcarse un mayor número de países, sobrepasando incluso barreras culturales e idiomáticas; la consecuencia inmediata es el aumento potencial del número de lectores y su diversificación atrayendo a un publico no entendido en la materia; y, por último, ante la posibilidad de abrir foros o de conectar con los autores mediante e-mail, provoca una beneficiosa capacidad de retroalimentación o feedback alrededor de cada artículo ${ }^{19}$.

Hasta hoy existen varios tipos de revistas electrónicas accesibles en línea: las revistas electrónicas exclusivas, las versiones paralelas de revistas de formato papel con texto completo o parcial, las que ofrecen el sumario más los resúmenes y las que sólo disponen del sumario.

El complemento eficaz a la edición electrónica es la digitalización de las revistas. Tenemos varios ejemplos eficaces, bien recuperando títulos desaparecidos, o bien rescatando números anteriores de revistas activas. En ambos casos se consigue liberar una pequeña parte del patrimonio bibliográfico para su consulta universal. Esta actividad, generalmente, está siendo desarrollada por incipientes bibliotecas virtuales o por instituciones regionales de investigación. Atendiendo al primer tipo, el modelo ejemplar es el desarrollado por la Biblioteca Virtual Miguel de Cervantes de la Universidad de Alicante, destinada a recuperar, o cobijar, revistas de distinta índole, incluyendo entre otros títulos prestigiosos como Sharq Al-Andalus o el Boletín de la Real Academia de la Historia. Con respecto al segundo modelo citaremos el ejemplo del Instituto de Estudios de Castilla-La Mancha, con las revistas Wad-al-Hayara y Al-Basit.

19 Malalana Ureña, Antonio: «Revistas electrónicas. Contradicciones económicas y legales». I Jornadas profesionales sobre publicaciones electrónicas de Biblioteconomía y Documentación. Madrid, UCM, 2003. 
Un trabajo distinto es el iniciado por Francisco Fernández Izquierdo. Dentro del proyecto «Historia y las Nuevas Tecnologías de la Información», han sido creadas una serie de bases de datos referenciales para recuperar los contenidos completos de varias revistas del CSIC, entre las que se encuentran Hispania e Hispania Sacra.

A pesar de todo, la novedad fundamental aportada por la edición electrónica es la libertad de expresión; quizás apoyada por el abaratamiento de costes al desaparecer de los presupuestos la impresión y la distribución. El coste cero ha propiciado la aparición de una serie de títulos, en un número no desdeñable, creados y mantenidos a título personal, o al margen del control de los grandes nombres, de los departamentos universitarios o de los institutos de investigación.

Aunque la mayoría se adaptan perfectamente a lo que tiene que ser una publicación periódica; en otros casos en ningún momento adoptan la definición ortodoxa: publicación seriada, que expresa sus contenidos mediante el artículo, que trata temas de distinta índole, pero siempre desde una perspectiva científica, técnica, profesional o divulgativa. Aquí podríamos incluir, una serie de sitios autodenominados revistas. El principal objetivo perseguido es abrir la participación a cualquier tipo de público para que aporte opiniones o ideas. La intención es interesante pero arriesgada, pues falta calidad en los escritos: entre otros defectos, se observa la reiteración de ideas sobradamente conocidas y cuando aparecen propuestas, aparentemente originales, no aportan nada nuevo sobre el tema cuestionado. Quizá, el sitio más adecuado para este tipo de experiencias son los foros de discusión o los webs sites personales o participativos.

Encontrar revistas en formato electrónico editadas por los departamentos o por las asociaciones y organizaciones es infrecuente, a lo sumo dispondríamos de ediciones paralelas. $\mathrm{O}$, en su caso, por problemas económicos graves, la edición en papel se convierte en electrónica. Aparentemente, el factor económico es el que puede transformar radicalmente la edición de revistas científicas editadas por instituciones dedicadas a la investigación, fundamentalmente la universitarias. Todo parece indicar que a lo largo de los próximos años, los títulos ahora disponibles abandonarán el formato papel y adoptarán el digital, para convertirse en portales de intercambio de conocimiento. Queda por ver, si esta labor necesaria, pero exigente en cuanto a horas de trabajo, puede ser asimilada por los departamentos y los institutos tan acostumbrados al trabajo individual; o si los editores están dispuestos a delegar competencias a jóvenes investigadores, para que libremente, diseñen los contenidos.

Y, por último, la implantación de las nuevas tecnologías no supone realmente un coste cero, pues es necesaria cierta inversión en equipos, sobre todo para la digitalización de trabajos, ya sean los incluidos en los números anteriores o, simplemente la edición facsímil de libros o textos relativos al tema de la revista. En este caso, tendríamos que conocer todos los aspectos relativos a los derechos de autor y de las editoriales.

Cualquier labor que se esté haciendo hoy, o la que podremos desarrollar en el futuro inmediato contará con un obstáculo: el vacío normativo respecto al 
depósito legal. La ley que regula esta obligación todavía no ha incorporado las nuevas implicaciones Internet. Este medio de comunicación es el único formato empleado para la creación de patrimonio bibliográfico. Al no existir la obligación del depósito legal de este formato, dicho patrimonio está condenado a desaparecer. Por lo tanto, la reconversión de las revistas hacia la edición electrónica puede suponer un gran avance en el intercambio del conocimiento, pero un gran retroceso en lo referente a la pervivencia de aquellos en el tiempo.

En definitiva, dejando a un lado las revistas que utilizan Internet como medio de propaganda para promocionar la venta de los números nuevos, nos quedamos con aquellas que han nacido al amparo del formato digital o han sido reconducidas hacia la red. En cuanto a los temas, tenemos de todos los tipos, igualmente pasa con los países, las hay de todas las nacionalidades, aunque el porcentaje abrumador son las de lengua inglesa, preferentemente norteamericanas. Comentario a parte, es el caso brasileño, con editoriales prolijas, tanto en Historia como en Literatura Medieval.

Comparativamente hablando, el caso español aparece a la cola, característica en consonancia con la escasa aportación de España al intercambio de conocimiento a través de Internet. Los títulos disponibles tratan mayoritariamente temas de literatura medieval, salvo el ejemplo de Cuadernos de Historia Medieval, un magnífico portal dedicado a la historia medieval; no era una simple revista, sino que también contaba con secciones dedicadas a la edición electrónica de monografías y de colecciones documentales. Desgraciadamente, aunque el formato de la web ha sido renovado, en cuanto los contenidos, todo parece indicar que la actualización de contenidos está interrumpida.

La literatura medieval, desde el portal Parnaso, está consiguiendo excelentes resultados, con las revistas Lemir, Memorabilia y Tirant lo Blanch.

Desafortunadamente, el resto de los títulos son de otros países, como las italianas Archeología Medievale, Ressegna Storica online y Reti Medievali; la británica Arthuriana; la francesa Le médévaliste et l'orinateur; o las norteamericanas Essays Medieval Studies y The Medieval Review.

Otra perspectiva muy distinta es la que transmite las revistas generales de historia, las multidisciplinares o las especializadas. Los mejores ejemplos son Clio, Islam y Al-Andalus, Qüern y WebIslam. Y desde fuera de nuestras fronteras Cabiers d'Historia, Essay in History, Archeologia dell'Architettura, Revista Portuguesa de Arqueología, Journal of Arabic and Islamic Studies, Mirabilia, etc.

El porcentaje de revistas españolas digitales de Edad Media o con contenidos de Historia Medieval es ridículo si la comparamos con las que se editan, hoy en día, en papel. Esta comparación no mejora si la establecemos lo hacemos con el total de todos los títulos editados en el resto de los países. Pero todavía es más grotesco si establecemos equiparaciones con otras áreas del conocimiento como las científicas y técnicas, o como las ciencias de la información. 


\subsection{Directorios}

- Repertorio <http://www.storia.unifi.it/_RM/repertorio/riv/>. Magnifico repertorio de revistas creado por Andrea Barlucchi detro del Reti Medivali. El índice, que incluye tanto las revistas en papel, como las de formato digital, ordenado por orden alfabético, además del título, incluye fecha del primer número junto a los datos de los editores.

- The History Journals Guide <http://www.history-journals.de/>. Stefan Blaschke ha creado, dentro de la WWW-Virtual Library, un directorio de revistas de historia; en total recoge 2.800 registros ordenados alfabéticamente, por etapas históricas, por idiomas, por ámbitos geográficos, etc. Lógicamente, puede consultarse como Europa medieval.

- Revistas de Edad Media <http://www.gratisweb.com/jmaiz/revistas cast.html>. Índice de revistas españolas que tienen relación con la Historia Medieval preparado por J. Maíz Chacón de la UNED en Palma de Mallorca. Organizadas en cuatro áreas, Historia Medieval, Arte y Arqueología, Historia de la Religión, Filosofía Medieval y Mundo Musulmán y Hebraico, incluye la fecha de inicio de su publicación junto a los datos de los editores, sean o no ediciones digitales.

\subsection{Revistas de historia medieval con formato electrónico (índices, resúmenes y textos) ${ }^{20}$}

- Alcanate. Revista de Estudios Alfonsíes <http://www.us.es/dhmcthus/alcanate. htm $>$. Temática: Estudios entorno a la figura de Alfonso X.

- Anuario de Estudios Medievales <http://www.imf.csic.es/Medievales/ anuario/01.htm $>$. Temática: general.

- Aragón en la Edad Media <http://fyl.unizar.es/Medieval/PubPeriod. htm>. Temática: estudios de Aragón en la Edad Media.

- Archeologia medievale. Cultura Materiale Insediamenti Territorio <http:// 192.167.112.135/NewPages/edAM.html>. Temática: arqueología medieval de Italia.

- Arthuriana. The Journal of Arthurian Studies < http://smu.edu/arthuriana/ arthuracc.htm $>$. Temática: saga artúrica y sus derivaciones desde la Edad Media hasta nuestros días

- Bibliografía de Studia Lullina, antes Bibliografía de Estudios Lulianos $<$ http://orbita.bib.ub.es/llull/sl.asp>. Temática: recopilación bibliográfica relacionada Ramon Llul.

20 Algunas de estas revistas se encuentran en texto completo en servicios de información como Periodicals Index Online <pio.chadwick.co.uk>. Las referencias siguientes se refieren a las páginas propias de las revistas. 
- Cabiers de Civilisation Médiévale: Xe-XIIe siècles <http://www.mshs. univ-poitiers.fr/cescm/publications/ccm/ $>$. Temática: trabajos de carácter interdisciplinar dedicados al mundo del Románico (siglos X-XII).

- Castillos de España <http://www.castillosasociacion.es/Revista-menu.htm >. Temática: estudio interdisciplinar sobre las fortificaciones, fundamentalmente peninsulares.

- La Coronica. A Journal of Medieval Spanish Language and Literature $<$ http://college.holycross.edu/lacoronica/ $>$. Temática: lengua y literatura medieval española.

- Cuadernos templarios < http://www.cuadernostemplarios.com.ar/>. Temática: El estudio de la orden del Temple desde todas las perspectivas y en todos los tiempos.

- Edad Media. Revista de Historia < http://www.uva.es/medieval/publicaciones. htm\# revista $>$. Temática: general.

- En la España Medieval <http://www.ucm.es/BUCM/revistasBUC/portal/ modules.php? name $=$ Revistas2\&id $=$ ELEM $>$. Temática «Dedicada a la Historia Medieval en todos sus campos y aspectos, con especial referencia a los reinos hispánicos, Al-Andalus y ámbitos próximos a la Península Ibérica».

- Essays Medieval Studies <http://www.luc.edu/publications/medieval/ index.html>. Temática: general.

- Exemplaria: a journal of theory in medieval and Renaissance studies <http:// www.english.ufl.edu/exemplaria/ $>$. Temática: Revista dedicada a estudios del Medievo y del Renacimiento.

- Historia. Instituciones. Documentos < http://www.us.es/dhmcthus/hid1.htm>. Temática: "publicación miscelánea de carácter anual que, como el título de la colección indica, da cabida a trabajos de indole histórica, histórico-institucional, ediciones de documentos escritos o de interés metodológico, referentes especialmente al período anterior a la disolución del Antiguo Régimen».

- Lemir. Revista de Literatura Española Medieval y del Renacimiento <http:// parnaseo.uv.es/Lemir.htm $>$. Temática: Literatura medieval española.

- The Medieval Review <http://www.hti.umich.edu/t/tmr> y <http:// www.hti.umich.edu/b/bmr/tmr.html $>$. Temática: publicación dedica a difundir recensiones de trabajos del medievalismo y se difunde por lista de correo. Anteriormente denominada The Bryn Mawr Medieval Review.

- Le médiévaliste et l'ordinateur <http://irht.cnrs-orleans.fr/medieviste. htm $>$. Temática: reunir a los medievalistas interesados en aplicación de las tecnologías de la información en la investigación de la Historia Medieval

- Medievalismo. Boletín de la Sociedad de Estudios Medievales. <http://www. us.es/dhmcthus/medievalismo.htm $>$. Temática: Historia de España.

- Medievalismo digital <http://www.medievalismo.org/sociedades/revistas/ medievalismodigital.htm $>$. Temática: información semanal de las actividades que se desarrollan en torno a la Edad Media. 
- Memorabilia. Boletín de Literatura sapiencial < http://parnaseo.uv.es/ Memorabilia.htm $>$. Temática: literatura sapiencial.

- Mirador < http://www.cc.jyu.fi/ mirator/>. Temática: estudios multilingüísticos de historia medieval.

- Miscelánea de los Cuadernos de historia medieval < http://www.uam.es/ departamentos/filoyletras/hmedieval/Cuader ini.htm $>$ Temática: «Órgano de publicación de las investigaciones de los miembros de este Departamento». Aunque recientemente ha sido renovada la imagen de la web, la revista sigue anclada en el número correspondiente al año 1999.

- Rassegna Storica online < http://www.storiaonline.org/mi/rassegna.htm >. Temática: investigación histórica e historiográfica de Italia.

- Revista d'Història Medieval < http://www.medievalismo.org/sociedades/ revistas/revistadhistoria.htm $>$. Temática: general.

- Revista Española de Filosofía Medieval < http://www.unizar.es/sofime/Revista Index.html $>$. Temática: El pensamiento

- $\bar{R}$ eti Medievali. Rivista <http://www.storia.unifi.it/_RM/rivista/>. Temática: historiografía y fuentes de información.

- Sharq Al-Andalus. Estudios Árabes < http://cervantesvirtual.com/hemeroteca/ sharq/>. Temática: "publicar fundamentalmente trabajos de investigación bistóricos relativos a las tierras del Levante de la Península Ibérica en época musulmana». A partir del número X-XI también se centra en los estudios de los mudéjares y de los moriscos.

- Tirant lo Blanch y la Ficción Caballeresca <http://parnaseo.uv.es/Tirant. htm $>$. Temática: literatura caballeresca.

5.3. Revistas de contenidos generales que incluyen artítulos relativos a la edad media

- Al-Andalus Magreb <http://biblioteca.uca.es/ucadoc/revuca.asp?rev= $11338571>$ Temática: estudios árabes e islámicos de al-Andalus y el Norte de África.

- Al-Basit. Revista de Estudios Albacetenses <http://www.uclm.es/ceclm/ DOCUMENTACION\%20VIRTUAL/Albasit/>. Temática: estudios de investigación sobre la provincia de Albacete.

- Alharaca. Revista Electrónica de Estudios Árabes y Mediterráneos <http:// www.uam.es/departamentos/filoyletras/earabes/alharaca/alharaca.htm $>$. Temáticas: información cultural hispano árabe.

- Almud. Revista de Estudios de Castilla-La Mancha <http://www.uclm.es/ ceclm/DOCUMENTACION\%20VIRTUAL/Almud/ $>$. Temática: Estudios de la región castellano manchega.

- Al-Qantara. Revista de Estudios Árabes <http://www.eea.csic.es/qantara/ qantara.html>. Temática: «estudios sobre el Islam en la Península Ibérica, en 
todos sus aspectos bistóricos, culturales y sociales, junto a una apertura bacia temas y ámbitos geográficos más amplios, especialmente al Norte de África y al Islam clásico. Los límites cronológicos son los siglos VII al XVII. Incluye además artículos de arqueología y arte islámicos».

- Archeologia dell Architettura. Cultura Materiale Insediamenti Territorio < http:// 192.167.112.135/NewPages/edAA.html>. Temática: arqueología de la arquitectura, principalmente de Italia.

- La Aventura de la Historia < http://www.el-mundo.es/ladh/>. Temática: Divulgación.

- Boletín de la Real Academia de la Historia < http://www.cervantesvirtual. $\mathrm{com} /$ hemeroteca/brah/index.shtml>. Temática: "constituye el elemento de conocimiento y difusión de las actividades académicas, no sólo las investigadoras, sino también de cuantas noticias genera la Corporación, así como sus dictámenes beráldicos y monumentales».

- Cabiers d'Histoire <http://www.revues.org/cahiers-histoire>. Temática: Historia Universal.

- Clio. Revista de Material Didáctico de Historia <http://clio.rediris.es>. Temática: crear un depósito de materiales didácticos para la Historia.

- Cuadernos de Arte e Iconografía. «CAIFUE». <http://www.fuesp.com/revistas/ pag/cai.html > . Temática: difusión de arte y iconografía de España.

- Cuadernos de Historia del Derecho < http://www.ucm.es/info/hisdere/ cuaderno.htm $>$. Temática: Historia del derecho español.

- Cuadernos de Prehistoria y Arqueología < http://www.ffil.uam.es/pa/cuaderno. htm $>$. Temática: Trabajos de arqueología de la Península Ibérica y del Mediterráneo.

- Essays in History < http://etext.lib.virginia.edu/journals/EH/>. Temática: recoge los trabajos de los graduados de la Universidad de Virginia.

- Hispania. Revista de Historia de España < http://www.ih.csic.es/publicaciones/ hispania.htm>. Temática: General. Gracias a la labor desarrollada por Francisco Fernández Izquierdo, para introducir las tecnologías de la información como una parte más del método de investigación histórica, ha sido creada una base de datos que recoge los índices de la revista. $<$ http://161.111.141.93/hispania/default.htm $>$. La estructura de la base de datos, además de disponer de los datos de autor, título y publicación, incorpora un resumen y descriptores temáticos, onomásticos y geográficos adjudicados tras la lectura de los textos.

- Hispania Sacra <http://www.ih.csic.es/publicaciones/hisacra.htm>. Temática: Historia de la Iglesia. Los índices de la revista en: <http://161.111.141.93/hispaniasacra/default.htm $>$. La estructura de la base de datos, además de disponer de los datos de autor, título y publicación, incorpora un resumen.

- Historia digital < http://www.historiadigital.com/>. Temática: Historia y Arqueología Universal. 
- Islam y Al-Andalus. Boletín electrónico < http://www.islamyal-andalus.org/>. Temática: cultura islámica.

- The Journal of Ecclesiastical History < http://titles.cambridge.org/journals/ journal_catalogue.asp? mnemonic $=\mathrm{ECH}>$. Temática: Historia universal de la Iglesia.

- Journal of Arabic and Islamic Studies < http://www.uib.no/jais/> Temática: recoge trabajos interdisciplinarios de la cultura islámica, que permite aportaciones presentadas en varios idiomas, incluido el castellano.

- The Journal of Theological Studies < http://www3.oup.co.uk/theolj/current/>. Temática: estudios teológicos.

- Revista ArqueoMurcia < http://www.arqueomurcia.com/revista/>. Temática: recoge las memorias de las intervenciones arqueológicas realizadas en la Región de Murcia

- Military History < http://www.historynet.com/mh/>. Temática: historia militar universal.

- Mirabilia. Revista Eletrônica de História Antiga e Medieval Journal of Ancient and Medieval History <http://www.revistamirabilia.com/>. Temática: Historia cultural del mundo antiguo y medieval.

- Prologus Baenensis < http://www.juanalfonsodebaena.org > . Temática: estudios sobre la poesía cancioneril de los siglos XV-XVIII.

- Qüern. Repertori bibliogràfic binnal de literatura $i$ llengua catalanes de l'edat mitjana $i$ l'edat moderna < http://biblioteca.udg.es/qüern>. Temática: recopilación de trabajos relacionados con la literatura y la lengua catalana.

- Revista de Estudios Extremeños <http://www.dip-badajoz.es/publicaciones/ reex/index.php $>$. Temática: edita trabajos que tratan temas de la provincia de Badajoz.

- Revista de Historia Militar <http://www.ejercito.mde.es/ihycm/revista/>. Temática: Historia militar universal.

- Revista Portuguesa de Arqueología <http://www.ipa.min-cultura.pt/ publicacoes/revista $>$. Temática: estudios de arqueología portuguesa.

- Revista Portuguesa de Historia <http://www1.ci.uc.pt/fluc/INSTITU/ IHES/REVISTA.HTM $>$. Temática: estudios de historia portuguesa.

- Signo. Revista de Historia de la Cultura Escrita <http://www2.uah.es/ historia1/signo.htm $>$. Temática: Historia de la Escritura.

- Traditio. Studies in Ancient and Medieval Thought, History, and Religion $<$ http://www.fordham.edu/traditio/ $>$. Temática: ediciones críticas de textos griegos y latinos, catálogos de manuscritos, junto a aspectos del mundo antiguo, de los orígenes de cristianismo y otros temas de la Edad Media.

- Wad-al-Hayara < http://www.uclm.es/ceclm/DOCUMENTACION\%20 VIRTUAL/WAD/>. Temática: publicación de estudios de investigación sobre la provincia de Guadalajara. 
- WebIslam <http://www.webislam.com>. Temática: revista de difusión para la comunidad musulmana, que incorpora con regularidad trabajos relacionados con al-Andalus.

\section{Biblioteca ViRTUAL: Libros ELECTÓNicos. ENSAYOS. ARTí́culos}

Al mismo tiempo que se creaban revistas electrónicas, también comenzaron a editarse monografías y ensayos digitales. Este formato ahorra costes y da salida a estudios que por su temática, excesivamente especializados, o por los criterios de selección de las editoriales no encuentran canales para su edición. Lógicamente podemos encontrarnos con testos de calidad discutible, pero como contrapunto tendríamos las tesis. Otro marco es la publicación, con un menor coste editorial y con una mayor difusión científica, de las actas de congresos, simposios, jornadas, etc. Igualmente, facilita la reedición facsimilar de títulos clásicos agotados desde hace tiempo. Dentro de esta labor estaría la recuperación de las fuentes documentales, como las crónicas, libros de viajes, etc., y aunque ya citamos algunos ejemplos, aquí podríamos diferenciar la publicación de textos históricos con ediciones anotadas o comentadas.

Un nivel distinto es la excelente utilidad que tiene este medio para los investigadores no adscritos a proyectos comunes y para los departamentos de universidades de Brasil y de Estados Unidos, pues consiguen, de esta forma, introducir más eficazmente sus trabajos en Europa.

En resumen, las bibliotecas virtuales y los archivos de enlaces sí han supuesto un cambio radical en la estrategia de la difusión de la investigación. Aún no contamos con las suficientes, pero ya es un camino sin no retorno. Un extraordinario ejemplo es la Ciberteca o motor de búsqueda que controla más de 54.000 documentos de todas las áreas temáticas. El siguiente ejemplo es el catálogo de tesis leídas en la Complutense, con más de 3.000 títulos disponibles. Pero, el proyecto más ambicioso y que mejores resultados esta cosechando es la Biblioteca Virtual de Miguel de Cervantes. Todavía tiene mucho camino por recorrer, pero, entre las tesis, construcción de portales temáticos, junto a la recuperación de textos clásicos, trabajos con prestigio y revistas punteras, se ha convertido en un punto de referencia en cualquier investigación. Desgraciadamente, quizá esté sustituyendo una función que debería estar cumpliendo la Biblioteca Nacional de España.

Ante esta utopía, tenemos que acudir a otros lugares, dispersos y dispares, como los disponibles en varios departamentos de historia o literatura de Brasil, The American Academy of Medieval Historians (AARHMS), Libro - proyecto de la Universidad de Arkansas-, los sitios para la cultura islámica y andalusí, o los más especializados como el portal dedicado a Gonzalo de Berceo, la página personal de Teresa de Castro concebida para la alimentación, o la consagrada a los tratados que Alfonso X, el Sabio, escribió sobre el juego del ajedrez. 
El siguiente bloque, es el que se refiere a textos de claro color regional: son páginas dedicadas a Navarra, Aragón, Galicia y Cataluña.

Por último, recogemos las actas, todavía escasas, de reuniones que analizaron temas tan dispares como la caminería, el miedo y la religiosidad en torno al milenio, estudios arqueológicos locales, etc.

\subsection{Temas generales}

- Ciberteca $<$ http://www.ciberoteca.com>. La Ciberteca en un proyecto de la Obra Social Bancaja. Entre sus objetivos se encuentra la creación de una biblioteca virtual recuperando la información disponible en Internet. Esto lo consigue estableciendo enlaces «directos a miles de obras digitalizadas de distinta temática, todas ellas libres de derechos». Entre más de 54.000 documentos podemos consultar algunos de temática medieval.

- Colección Digital Tesis de la UCM <http://cisne.sim.ucm.es/search* spi $\sim$ S2/g?SEARCH $=$ TESISDIG $>$. Se trata de la base de datos con los registros de 7.000 tesis leídas en esta Universidad entre los años 1900-2000, de las que 3.000 pueden ser consultadas directamente en formato PDF.

\subsection{Temas generales de historia medieval}

- Història Medieval <http://www.ricardocosta.com/>. Página personal de la profesor Ricardo da Costa, de la Universidad Federal do Espírito Santo (UFES) de Brasil, especializado en la figura de Ramon Llull, que recoge los textos de más de 50 trabajos de investigación relacionados con la Edad Media.

- Grupo de Trabalho de Estudos Medievais <http://www.grupodeestudosmedievais.cjb.net/>. Constituido en 1999 en Porto Alegre (Brasil) tiene como objetivo fomentar los estudios de la Edad Media en Brasil, así como su proyección internacional. Para ello, entre otros elementos, han colocado una serie de trabajos escritos por algunos de los miembros del grupo.

- Centro de Estudos Medievais Oriente \& Occidente <http://www2.fe. usp.br/\%7Ecemoroc/ $>$. Este centro fue creado en 2002 y depende del Departamento de Filosofia e Ciências da Educação, da Faculdade de Educação, da Universidade de São Paulo. Entre los materiales disponibles encontramos Special Collections. La primera denominada Middle Ages and Medieval Themes <http://www.hottopos.com/spcol/medieval.htm>, que cuenta con alrededor de 100 artículos escritos en siete lenguas, y la segunda, Arab Culture, Chinese Culture, Eastern Culture <http://www.hottopos. com/spcol/oriente.htm\#1>, también con numerosos artículos relacionados con el Islam. 


\subsection{Historia de la iglesia}

- Documentos para el estudio de la Historia de la Iglesia Medieval $<$ http://usuarios.advance.com.ar/pfernando/DocsIglMed/index.html $>$. Se trata de una página preparada por Fernando Gil y fray Ricardo Corleto como material de apoyo para la asignatura de Historia de la Iglesia II, que se imparte en la Facultad de Teología de la Universidad Católica Argentina. Se trata de la versión electrónica de trabajos ya editados en papel.

\subsection{General de España}

- The American Academy of Medieval Historians (AARHMS) < http://www. uca.edu/divisions/academic/history/aarhms/default.html $>$. Dispone de diferentes secciones de interés, como Archivo con documentos transcritos y traducidos al inglés y facsímiles.

- LIBRO. The Library of Iberian Resources Online <http://libro.uca.edu/ about.htm $>$. LIBRO es un proyecto de The American Academy of Research Historians of Medieval Spain and the University of Central Arkansas que tiene por objeto reeditar en formato electrónico una serie de trabajos de hispanistas. Por ejemplo, algunos de los estudios de J.C. Bishko, P.H. Freedman y T.F. Glick entre otros dedicados a la Reconquista, regadío, religiosidad, templarios, las Cortes, etc. Los textos están escritos en inglés.

- Biblioteca Virtual Cervantes <http://www.cervantesvirutal.com>. Dispone de material muy dispar, tanto trabajos de investigación, recientes o clásicos, como algunos facsímiles de crónicas, libros de viajes, textos literarios, etc. como: La Historia Medieval a través de los textos; Memoria sobre el Fuero de Madrid del año 1202 de Antonio Cavanilles y Centi; Descripción de España de Idrisi; Guerra de Granada de Alonso de Palencia, etc.

- Historical Text Archive <http://historicaltextarchive.com>. Interesante web que reúne, entre otras opciones, libros electrónicos, artículos, ensayos, documentos, fotografías y enlaces de Historia Universal. Con respecto a España contamos con una recopilación de enlaces que se corresponden con trabajos e investigación que incumben a distintas épocas y temas $<$ http://historicaltextarchive.com/links.php?op $=$ viewslink\&sid $=55>$.

- Cuadernos de Historia Medieval <http://www.uam.es/departamentos/ filoyletras/hmedieval/Cuader_ini.htm >. A finales de los 90 esta web fue una de las más atractivas. Cobijada y gestionada dentro del Departamento de Historia Medieval de la Universidad Autónoma de Madrid, ofrece distintos contenidos que se agrupan dentro de dos secciones: Docencia y Revista Miscelanea. Las dos son interesantes, aunque con distintos objetivos. La primera recopila fragmentos de textos históricos, mapas 
y enlaces recomendados para la historia medieval universal. En la segunda se ha creado Monografías y Colecciones documentales.

\subsection{Islam. Al-andalus}

- Biblioteca Virtual WebIslma. Biblioteca de Estudios Islámicos < http://www. webislam.com/bei/index.htm $>$. El portal de la comunidad islámica en España ha creado una biblioteca virtual que cuenta con diferentes textos organizados en siete grupos: Fuentes, Pensamiento, Sufismo, Historia, Arte y Literatura, Ciencias Políticas y Jutbas.

- Islam y Al-Andalus < http://www.islamyal-andalus.org/>. Web site de la Yama'a Islámica de Al-Andalus que contiene numerosos recursos. Además del Boletín informativo mensual, cuenta con varias secciones a tener en cuenta como la denominada Historia de Al-Andalus, $<$ http://www.islamyal-andalus.org/nuevo/historia/historia.htm >, con diferentes textos de investigación sobre este ámbito.

- Silves (Xelb), uma cidade do Gharb Al-Andalus: território e cultura <http:// www.ipa.min-cultura.pt/pubs/TA/folder/23>. Libro electrónico de Rosa Varela Gomes publicado en la sección Trabalhos de Arqueología del Instituto Portugués de Arqueología.

\subsection{España temático. Mundo antiguo. Lengua Castellana. Camino de Santiago. Alimentación. Arqueología. Alfonso X}

- Historia Antigua <http://www2.alcala.es/histant>. En la web del Departamento de Historia I y Filosofía, área de historia Antigua de la Universidad de Alcalá de Henares, encontramos digitalizados varios trabajos de algunos de los profesores, en concreto de María Elvira Gil Egéa (especialista en el mundo vándalo) y de Margarita Vallejo Girvés (Bizancio).

- Apuntes sobre el Camino de Santiago < http://www.geocities.com/urunuela25/ santiago/indice.htm $>$. Reedición en formato electrónico de una serie de trabajos, coordinados por el profesor Javier García Turza, dedicados al Camino de Santiago.

- Teresa de Castro's web http://www.geocities.com/CollegePark/Field/ 4664/. La Doctora de Castro ha creado un web personal donde ha ubicado una serie de textos, libros y artículos, dedicados fundamentalmente a la alimentación y el abastecimiento en el Reino de Granada.

- Archeologia de la all'Insegna del Giglio <http://192.167.112.135/NewPages/ EDITORIA.html> . Además de las revistas de arqueología medieval, esta web destaca por la recopilación de monografías dedicadas a la arqueología medieval italiana. 
- The Book of Games by Alfonso X, el Sabio <http://www.u.arizona.edu/ $\sim$ smusser/ljtranslation.html $>$. Estudio de Sonja Musser Golladay dedicado al juego del ajedrez.

\subsection{Por regiones. España. Aragón. La Rioja. Cataluña. Galicia. Nava- rra. Murcia}

- Sociedad Estatal para la Acción Cultural Exterior <http://www.seacex.com/ indexflash.htm $>21$.

- Atlas de Historia de Aragón <http://www.dpz.es/ifc/atlasH/atlas_indice. htm >. "Contiene 144 mapas históricos y otros tantos textos explicativos adaptados para su manejo informático. Asimismo facilita orientación bibliográfica y búsqueda onomástica a través de dos indices particulares (toponímico y antroponímico, con acepción en ambos casos de nombres antiguos y modernos)». El AHA es la versión electrónica reeditada en 1999 y que se corresponde con la edición impresa de 1992, que fue dirigida por Miguel Beltrán, José Luis Corral, Esteban Sarasa y Eliseo Serrano, de la Sección de Historia de la Institución Fernando el Católico ${ }^{22}$. Dispone de índices por épocas, por topónimos y por antropónimos; además recoge un índice completo con toda la bibliografía recomendada.

- La Rioja, tierra abierta <http://www.geocities.com/urunuela24/riojaabierta/rioja-abierta.htm $>$. Reedición, en formato digital, de algunos de los textos dedicados a la Edad Media riojana que fueron publicados en el catálogo de la exposición, La Rioja tierra Abierta, celebrada en Calahorra en el año 2000. Son textos de Javier García Turza, Enrique Cantera, $\mathbf{M}^{\mathrm{a}}$ Jesús Viguera Molins, Antonio Gonzalez Blanco, Ma Pilar Pascual Mayoral, Antonio Linaje Conde, Antoni González Blanco y Tomás Ramírez Pascual.

- Domus. Revista d'Història i Arqueología <http://www.geocities.com/ culom/ $>$. Esta mal llamada revista, cuenta con una sección que recopila trabajos de historia y arqueología medieval, cuya temática se centra en los siguientes ámbitos geográficos: Cataluña, Principado de Andorra, Islas Baleares, País Valenciano, etc.

21 La SEACEX viene organizando una serie de exposiciones, y de entre las que ya han concluido destacan: Memoria de Separad. Madrid: Sociedad Estatal para la Acción Cultura, 2002; Esmaltes medievales. De Limoges a Silos. [Madrid]: Sociedad Estatal para la Acción Cultura, 2001; Erasmo en España. La recepción del humanismo en el primer Renacimiento español. Madrid: Sociedad Estatal para la Acción Cultura, [2002]: Marruecos y España, una historia común; España Medieval y el legado de Occidente. De todas existe la versión digital de los textos que constituyen el catálogo, la visita virtual, el catálogo de las piezas y la audioguía que comenta, tanto la exposición como las piezas expuestas.

22 Beltrán, Miguel et al.: Atlas de Historia de Aragón, Zaragoza, Institución Fernando el Católico, 1991. 
- Carlos Barros <http://www.h-debate.com/cbarros/spanish/index2.htm>. En esta página personal cobijada dentro de Historia a Debate podemos encontrar numerosos trabajos, a texto completo, sobre historia medieval, especialmente referida a Galicia.

- Història de Catalunya <http://www.gencat.es/historia $>$. Breve reseña histórica de Cataluña desde sus orígenes hasta la actualidad. Destacan los siguientes capítulos: «Origen de les institucions polítiques catalanes», «Les Corts Catalanes i la primera Generalitat medieval (s. XIII-XIV)» y «Extinció de la dinastia catalana i distanciament de la monarquia (s. XV-XVII)».

- ArqueoMurcia < http://www.arqueomurcia.com/>. Esta web tiene como finalidad recoger toda la información generada por la arqueología murciana, donde se incluye distintas publicaciones on-line, como Memorias de arqueología o las jornadas.

\subsection{Actas de reuniones científicas}

- Congreso Internacional de Caminería Hispánica. Comunicaciones sobre CastillaLa Mancha. <http://biblioteca2.uclm.es/biblioteca/ceclm/libros/ camineria/\#> . El Centro de Estudios de Castilla-La Mancha, en colaboración con la Aache Ediciones, ha colgados las comunicaciones, cuya temática tenga como espacio geográfico esta región, presentadas a los cinco congresos de Caminería Hispánica celebrados hasta la fecha.

- Milenio: Miedo y Religión. IV Simposio Internacional de la Sociedad Española de Ciencias de las Religiones <http://webservices.ull.es/congresos/conmirel/ index.HTM $>$. Tenerife, Universidad de la Laguna, 3-6 de febrero del 2000.

- III Semana de Estudos Medievais <http://www.ifcs.ufrj.br/ pem/textos.htm>. Disponemos de algunos de los trabajos de este evento organizado en 1995 por Pem, Programa de Estudos Medievais de la Universidade Federal do Rio de Janeiro, Instituto de Filosofia e Ciências Sociais.

- I Jornades d'Història i Arqueologia Medieval del Maresme. L'Arquitectura militar medieval <http://www.geocities.com/Athens/Academy/4315/jornades/ ponencies/ponencies.html $>$. Resúmenes y algunos textos completos de las jornadas celebradas en 1999.

\section{GRANDES FOCOS DE INTERCAMBIO DEL CONOCIMIENTO}

En este momento entramos en el formato de mayor proyección y con mejores posibilidades para conseguir el objetivo de intercambiar el conocimiento ${ }^{23}$.

23 Es necesario aclarar, que algunos de los recursos que han sido incluidos en otros apartados podrían estar también presentes aquí. A veces es complicado establecer las preferencias, y estas se 
Lógicamente, estamos hablando del portal temático. Se trata de una reconversión factible, incluso para las revistas digitales, de tal manera que a los contenidos de cada número se añadirían otros elementos de valor añadido, como foros de debates relacionados con los artículos, inclusión de otros ensayos que no tuviesen cabida en la propia revista, recuperación de textos que tuviesen que ver con el tema de la revista, edición de monografías, igualmente relacionadas con la temática, etc. Un excelente ejemplo, frustrado, es Cuadernos de Historia Medieval.

En Internet, hoy en día, podemos disfrutar de varios portales propiamente dichos, más algunas páginas con similar orientación. Dentro de estos últimos deberíamos incluir los proyectos de investigación. Los más interesantes, y quizá los que mejor han aprovechado las posibilidades multimedia de las tecnologías de la información, son las reconstrucciones virtuales de edificios, conjuntos arquitectónicos y espacios urbanos desaparecidos. Como botón de muestra, citaremos las reconstrucciones de monumentos bizantinos, islámicos o las catedrales.

En cuanto a los portales temáticos, aún contamos con escasos ejemplos, en un porcentaje considerable, dominan los literarios, como los que plantean dos de los potenciados dentro de la Biblioteca Virtual Miguel de Cervantes: uno para la literatura mudéjar y morisca; y otro para La Celestina. Otros dos, también con su particularidad, son los relativos a la filosofía islámica y a las Órdenes Militares Peninsulares.

Hemos dejado para el final, con un comentario algo más extenso, a dos propuestas. La primera la dedicada a Gonzalo de Berceo. Un magnífico exponente de lo que deben ser los focos de difusión e intercambio del conocimiento. Cuenta con textos de las obras, ensayos, artículos, etc., relativos al escritor, pero también relacionados con el castellano, el marco geográfico, tanto el local como el regional, con el Camino de Santiago, etc. La segunda, Regesta Imperii, un ambicioso proyecto de recuperación de la historia europea a partir de los reyes romano-germánicos desde los Carolingios hasta Maximiliano I.

\subsection{Proyectos de investigación histórica}

- Coordinación de la Edición de Hagiografía Castellana (CEHC) < http://web. uniovi.es/CEHC/index.htm $>$. Este proyecto de la Universidad de Oviedo «nació para poner en contacto a los investigadores que trabajamos en la edición y estudio de la hagiografía castellana de la Edad Media y Siglo de Oro». La web dispone de la edición electrónica de trabajos dedicado a recopilación bibliográfica; así como a la edición de textos como el santoral conocido como manuscrito 8 de la Biblioteca de Menéndez Pelayo de Santander Flos sanctorum, datado en el siglo XIV.

\footnotetext{
han decidido en función de algunas de las características puntuales o por la selección de una parte del recurso, individualizándola en función de su interés.
} 
- Fuentes del Medievo Hispano <http://www.ih.csic.es/departamentos/medieval/ $\mathrm{fmh} /$ index.htm $>$. Proyecto dirigido por los doctores Isabel Alfonso Antón y Julio Escalona Monge del Departamento de Historia Medieval, del Instituto de Historia del CSIC. Como material dispone de la digitalización de la edición de determinadas fuentes narrativa, documentales, jurídicas, etc., como: Anales Castellanos, Crónica Albeldense, Crónica anónima de silos, una larga lista de fueros o el Obituario de la Catedral de Burgos.

- CRELOC. Clientela y Redes Locales en la Castilla Medieval <http:// www.creloc.net $>$. Dirigido por Cristina Jular en el Instituto de Historia del CSIC, con colaboradores de las Universidades Carlos III, Burgos y el Archivo Histórico Nacional, integra digitalización, transcripción, marcado de textos y preparación de los datos obtenidos en las fuentes para elaborar análisis prosopográficos, a partir de cartularios de los monasterios burgaleses de Santa María de Ríoseco y San Miguel de Villamayor de Treviño y diversos registros y memorias del linaje Velasco, con documentos de los siglos XI al XVI.

- Grup de Recerques en Antiguitat Tardana. GRAT < http://www.ub.es/ grat/grat01.htm $>$. El grupo GRAT de la Universidad de Barcelona tiene por objeto la investigación de la Antigüedad Tardía. Entre la información que propone aparecen numerosos artículos dedicados a este periodo, algunos de ellos sobre temática visigoda.

- The Sala Family Archives. A Hand List of Medieval and Early Modern Catalonian Charters <http://www.georgetown.edu/labyrinth/professional/pubs/ sala/> . Proyecto desarrollado desde 1996 por Jessica-Julia Vitz a partir de una tesis escrita por Joseph J. Gwara en 1982-1983. El objetivo es recuperar una colección de manuscritos de Cataluña descubiertos en 1980 en la Biblioteca de la Universidad de Georgetown. Se trata de un conjunto de 289 documentos cuya cronología se inicia en 1261 y concluye en 1690. Además de ofrecer en su introducción información exhaustiva del fondo, también dispone de una veintena de ejemplos que incluye trascripción e imagen digitalizada del documento original.

- Grupo de Investigación en Arqueología de la Arquitectura <http:// www.ehu.es/arqueologiadelaarquitectura/castellano/index.php $>$. Grupo de investigación radicado en la Universidad del País Vasco.

- Grupo de Investigación Toponimia, Historia y Arqueología del Reino de Granada < http://www.ugr.es/ tharg/>.

\subsection{Arte. Arquitectura. Arqueología. Urbanismo}

- Cluny <http://www.rzw.ch/kultur/kultur.htm>. Reconstrucción virtual de la abadía de Cluní. Textos en alemán.

- Catedral de Santiago de Compostela <http://www.cvrlab.org/projects /real_time/santiago_compostela/santiago_compostela.html\#top $>$ y http:// 
www.ats.ucla.edu/news/spotlight.htm\#CathedralSantiagoCompostela $>$ Reconstrucción virtual del edificio medieval creada por UCLA Cultural VR Lab

- Reconstrucción del Coro Pétreo de Maestro de la Catedral de Santiago de Compostela <http://www.fbarrie.org/fundacion/webcoro/inicio.htm>. Reconstrucción virtual del coro facilitada por la Fundación Pedro Barrié de la Maza.

- Arte románico en Navarra <http://www.romanicoennavarra.info/>.

- Castillos de Soria <http://www.castillosdesoria.com/>.

- Isfahan <http://isfahan.anglia.ac.uk/isfahan.html>. Interesante visión del conjunto arquitectónico de Isfahan en Irán.

- El Alcázar Omeya de Aman <http://www.eea.csic.es/Alcazar/home. html >. Una misión española ha estado trabajando en el Palacio Alcázar Omeya de Amman. El proyecto dirigido por Antonio Almagro, es una buena propuesta de reconstrucción virtual que recupera, partiendo de los restos arqueológicos, la arquitectura y el urbanismo de este conjunto.

- Archaeological Collaboration for Research \& Excavation ACRE < http:// www.acrearchaeology.org/ $>$. A lo largo de los noventa se desarrollaron una serie de trabajos arqueológicos en la ciudad de Beirut (Líbano), en concreto el proyecto se denomina Beirut - the Souks project correspondiente al área BEYOO6, que entre otros resultados se encuentra el hábitat bizantino. Aquí podemos encontrar todo el proceso metodológico, los resultados, el estudio de los materiales arquitectónicos y muebles. Asimismo se incluye bibliografía publicada en torno al proyecto; así como enlaces a otras áreas también excavadas. El complemento a todo esta información la encontramos en la web del DDC de la Universidad Americana de Beirut <http://ddc.aub.edu.lb/>.

- Yacimiento de la Plaza de Ramales (Madrid) < http://www.madrid.org/ dgpha/patrimonio arqueologico/actuaciones/ramales.htm\# $>$. Empleando los formatos html y flash es posible hacer un seguimiento de las excavaciones arqueológicas realizadas (1999-2000) en esta plaza madrileña encaminadas a la documentación de la parroquia de San Juan.

- The Media Visual Center <http://www.mcah.columbia.edu/>. Este instituto pertenece al Departamento de Arte, Historia y Arqueología de la Universidad de Columbia. El proyecto se dedica a la recuperación digital de diferentes elementos relacionados con la historia del arte. Con respecto a la historia medieval, como: edificios religiosos (Santa Sofía, Notre-Dame, Amiens < http://www.learn.columbia.edu/Mcahweb/index-frame.html >), recuperación de ciudades (Roma y París), conjuntos (Alambra $<$ http://www.mcah.columbia.edu/alhambra/flash/start.html >). Para saborear mejor esta página es necesaria la instalación de los programas Quictime 4.0 y Flasch 5. Algunos de los ejemplos necesitan suscripción. 
- Mezquita de Córdoba <http://cvc.cervantes.es/actcult/mezquita cordoba/indice.htm $>$. Propuesta ubicada en el sitio del Centro Virtual Cervantes, con una visita virtual por la mezquita.

- Arqueología medieval <http://www.arqueologiamedieval.com/>. Sitio dedicado a las actividades arqueológicas realizadas fundamentalmente en la provincia de Granada.

- ArqueoCórdoba <http://www.arqueocordoba.com/>. Análisis de la historia de Córdoba a través de la arqueología.

- Antropos. Arqueología y Antropología <http://www.antroposclm.com>. Empresa de arqueología fundada en 1994. Incluye numerosos textos, fruto de su actividad en Castilla-La Mancha.

- The Jerusalem Archaeological Park < http://www.archpark.org.il/index.asp>. Sitio creado por Israel Antiquities Authority y, aunque esta distando a la Jerusalem judía, cuenta con información que puede tener su valor para todas las épocas de la Historia Medieval.

- Design Integration Laboratory <http://www.designlaboratory.com/>. Organización dedicada a formación en el campo de la arquitectura. En uno de los curso Course and Training Archives, Architecture 222, Introduction to Architectural Computer Graphics, conducido por el prof. Kevin Matthews, aparecen una serie de proyectos fin de estudios. Alguno de los alumnos han reconstruidos una serie de monumentos, como: El castillo de Dovert en Kent, la catedral de Pisa y Santa Maria del Naranco.

- Alcami < http://museums.ncl.ac.uk/alacami/alacami.htm>. Descripción de la excavación y reconstrucción virtual de la iglesia Alcami en Sicilia.

- Byzantium $1200<$ http://www.byzantium1200.com>. Extraordinario proyecto destinado a la recuperación virtual de una serie de edificios o conjuntos arquitectónicos construidos en Estambul. La idea es reproducir el sistema de la maqueta de Roma a partir del plano-vista de Allan Sorell.

- Byzantine Architecture Projet <http://www.princeton.edu/ asce/ const_95/const.html $>$. Proyecto desarrollado por el profesor Ahmet Cakmar del Departamento de Civil Engineering and Operations Research de la Universidad de Pricenton. Aquí se observa el desarrollo de las investigaciones de la arquitectura erigida en el Hagia Sophia. Las reconstrucciones virtuales ayudan a comprender las construcciones de esta época.

- Baptisteria Sacra: An Iconographic Index of Baptismal Fonts (BSI) <http:// www.library.utoronto.ca/bsi/ $>$. BSI es un proyecto independiente, afiliado a Iter:Gateway to the Middle Ages and Renaissance project de la University of Toronto, iniciado en 2001. Se trata de crear un índice que recoja la iconografía de fuentes bautismales, abarcando desde el nacimiento del Cristianismo hasta el siglo XVII. El proyecto dispone de una base de datos con la información recopilada hasta la fecha. Además, de campos abiertos, dispone de campos guiados y de un listado de los objetos ordenada alfabéticamente. Con respecto a cada pila bautismal, junto a su fotografía, se 
aportan datos complementarios de gran valor, como: la localización, cronología, descripción, dimensiones, referencias en trabajos de investigación y bibliografía; así como enlaces cruzados a ejemplos similares.

\subsection{Portales temáticos}

- Regesta Imperri Online <http://www.regesta-imperii.org/>. Es un proyecto que tiene como finalidad la realización de un inventario de los documentos y fuentes historiográficas de los reyes romano-alemanes desde los Carolingios hasta Maximiliano I y de los papas. Se trata de un recurso imprescindible para el estudio de la historia de Alemania y de Europa en donde se puede consultar todos los volúmenes publicados en Regesta Imperii. Cuenta además con varias bases de datos, como la dedicada a la bibliografía de historia de la Edad Media europea o la de monografías.

- Gonzalo de Berceo. Obras completas < http://www.vallenajerilla.com/ berceo/>. Esta web dispone de interesantes trabajos de investigación dedicados a Berceo y a su época, etc. Igualmente, también incluye otros estudios dedicados a San Millán (personaje y lugar) y al nacimiento del castellano. Todos los textos son reediciones de artículos o ponencias publicadas en libros, congresos, revistas, etc. Al mismo tiempo, posibilita los enlaces a otras paginas web, como la dedicada a Mil años de Castellano, La Rioja, tierra abierta, Glosas Emilianenses o sobre el camino de Santiago.

- Cantar del Mio Cid <http://www.cervantesvirtual.com/bib_obra/Cid/>. Dispone del manuscrito digitalizado de Per Abbat, trascripción, y edición facsimilar del Cantar; así como, una amplia recopilación bibliográfica y de recursos web.

- Literatura de mudéjares y moriscos < http://cervantesvirtual.com/portal/ $\mathrm{LMM} />$. Portal desarrollado dentro de la Biblioteca Virtual Miguel de Cervantes. El objetivo de este sitio es dar a conocer la producción literaria de esta minoría étnica entre los siglos XIV-XVII. Aparentemente, como responsable del trabajo aparece M. J. Rubiera Mata. Aquí se dispone de abundante material de textos y de trabajos de investigación. Aunque todas las secciones o epígrafes está desarrollado, es una apuesta inteligente para fomentar la investigación con respecto a esta temática.

- The World of Dante < http://jefferson.village.virginia.edu/dante/>. Editado por Deborah Parker, proyecto dedicado al Infierno de Dante.

- Brasil 500 anos http://bnd.bn.pt/ed/viagens/brasil/index.html>. La Biblioteca Nacional Digital de Portugal ha creado un portal dedicado al quinto centenario de Brasil, aunque este a su vez se encuentra dentro de un trabajo de mayor envergadura: As viagens dos portugueses (2001). En el apartado dedicado a los antecedentes aparecen los tratados de Alcàçovas (1479) y Tordesillas, con la digitalización del documento junto a la tras- 
cripción del texto; así como otros temas relacionados con la navegación y los descubrimientos.

- La Celestina <http://www.cervantesvirtual.com/bib obra/celestina/>. Portal temático dependiente de la Biblioteca Virtual Miguel de Cervantes y dirigido por Marta Haro, Rafael Beltrán y José Luis Canet (Universitat de Valencia): dispone de ediciones de la obra, de trabajos de investigación, de imágenes digitalizadas, de documentos sonoros y de catálogo de enlaces.

- Centro de documentación Juan Alfonso de Baena <http://www. juanalfonsodebaena.org $>$. Portal dedicado al cancionero y al mundo medieval español del siglo XV. Dispone una base de datos con el material disponible, la revista electrónica Prologus baenensis, la descripción del manuscrito de Baena y selección de enlaces temáticos.

- Islamic Philosophy Online <http://www.muslimphilosophy.com>. Web dedicada a la filosofía islámica, y por la información disponible, preferentemente a la filosofía medieval. Para ello ha seleccionado una serie de pensadores, recopilando una parte importante de textos, así como distintos trabajos de investigación sobre las figuras o ideas: Al Farabi, Avicena, Abu Hamid al-Ghazali, Abu'l Walid Muhammad Ibn Rushd Al-Qurtubi. Averroes o Ibn Taymiyah. Indistintamente también dispone de otros documentos, como diccionarios y la revista Journal of Islamic Philosophy.

- The Portuguese Military Orders <http://www.geocities.com/Athens/Academy 13908/militaryorders/index.html $>$. J. Vicente de Bragança ha creado un interesante sitio dedicado, no sólo a las Ordenes Militares portuguesas, sino a las Ordenes Militares peninsulares, donde se explica con toda claridad el nacimiento e historia de las distintas Órdenes, completado con una extensa bibliografía y una oferta de links. Igualmente, este sitio cuenta con The Cyber Journal of Heraldic Bookplates editado por el propio Bragança junto con J. Stewart LeForte.

- Ménestrel: Médiévistes sur l'Internet. Sources, Travaux, Reférences en Ligne $<$ http://web.ccr.jussieu.fr/urfist/mediev.htm > . Ménestrel es otro de los buenos sitios dedicados a ofrecer recursos a los interesados por la Historia Medieval, con la diferencia de que en esta ocasión ha sido creado por europeos, en concreto a partir del equipo de «Médiéviste et l'Ordinateur».

- Storia on line. <http://www.storiaonline.org/ma/>. Proyecto de historia medieval europea, principalmente, de Inglaterra, Italia, España y Portugal, donde, entre otras cosas se ha creado un foro de discusión y distintos recursos, como enlaces, revistas, etc. Este proyecto está relacionado con proyectos similares desarrollados para la Península Ibérica y el Reino Unido.

- Simulacra Romae < http://www.simulacraromae.org/>. A pesar de tratarse de un portal temático dedicado al mundo romano hispánico, cuenta en ocasiones, como por ejemplo Mérida, con artículos o informes de excavaciones de cronología medieval. 


\section{PAgINAS WEB CORPORATIVAS Y DEPARTAMENTALES}

Cuando comenzamos la andadura por el mundo Internet cabía la posibilidad de que las instituciones y asociaciones dedicadas a la investigación de la Historia Medieval, junto a los departamentos y áreas departamentales universitarias serían puntos de referencia obligatorios. Sin embargo, la realidad demuestra que esto no es así. Salvo ejemplos extraordinarios, la selección que aquí se recoge confirma que las páginas web, cuando existen, cumplen el mínimo requisito de la información organizativa o institucional. Entre todas ellas, cabe destacar el Departamento de Estudios Medievales de la Institución Milá y Fontanals y el Departamento de Historia Medieval y Ciencias y Técnicas Historiográficas de la Universidad de Sevilla.

\subsection{Instituciones de investigación}

- Departamento de Estudios Medievales de la Institución Milá y Fontanals de CSIC en Barcelona <http://www.imf.csic.es/Medievales/paginas/ Principal.htm $>$. Información sobre las publicaciones y las líneas de investigación desarrolladas par el Departamento. Entre los trabajos puestos en marcha destaca la base de datos Repertorio del Medievalismo Hispánico.

- Escuela de Estudios Árabes del CSIC < http://www.eea.csic.es/>. Web corporativa. Entre otros materiales dispone de los índices de la revista Al-Qantara y del proyecto de reconstrucción digital del palacio de Amman en Jordania.

- Instituto del Patrimonio Histórico Español del Ministerio de Educación Cultura y Deporte de España < http://www.cultura.mecd.es/patrimonio/ iphe/institutoPatrimonioHistorico.jsp $>$. Web institucional. Dispone una biblioteca virtual, un directorio de enlaces, acceso al catalogo bibliográfico, información sobre las actividades de restauración del patrimonio mueble e inmueble (catedrales, arquitectura militar y religiosa), etc. Parte de la gestión de información se centraliza a través del Servicio de Documentación.

- Real Academia de la Historia < http://www.rah.es > Web corporativa.

- Casa de Velázquez < http://www.casadevelazquez.org >. Web corporativa.

- Fundación Sánchez Albornoz <http://www.fsanchez-albornoz.com>. Web corporativa.

- Centre d'Études Supérieures de Civilisation Médiévale <http://www. mshs.univ-poitiers.fr/ces $\mathrm{cm} / \mathrm{ces} \mathrm{cm}$.htm $>$. Unidad mixta de CNRS y la Universidad de Poitiers que edita los Cuadernos de Investigación Medieval. Web corporativa. 
- Instituto portugués de Arqueología del Ministerio de Cultura de Portugal <http://www.ipa.min-cultura.pt $>$. Web corporativa. Interesante sitio dedicado a la arqueología portuguesa que ofrece una completa información de sus actividades, sobre todo a través de varios organismos, como el Centro Nacional de Arqueología Náutica e Subaquática (CNANS). Por otro lado, facilita el acceso a la investigación mediante una serie de publicaciones, monográficas denominada Trabablos de Arqueologia y artículos en la Revista portuguesa de Arqueologia. Par ultimo, incluye una base de datos, denominada Endovelico.

- Centro de Estudios del Románico <http://www.santamarialareal.org >. La Fundación Santa María la Real, con sede en Aguilar de Campoo (Palencia), ha creado un Centro de Estudios del Románico. Web institucional. Dispone de un diccionario de términos relacionados con el Románico.

\subsection{Asociaciones}

- Sociedad de Estudios Medievales <http://www.us.es/dhmcthus/seem. htm $>$. Web corporativa.

- Asociación Hispánica de Literatura Medieval (AHLM) < http://griso.cti. unav.es/medieval/ahlm/principal.html $>$. Web corporativa. Incluye dos bases de datos. Una que recoge el boletín bibliográfico y otra con el listado de socios.

- Asociación Española de Amigos de los Castillos <http://www. castillosasociacion.es/index.htm $>$. Web corporativa.

- Society for the Study of the Crusades and the Latin East <http:// freespace.virgin.net/nigel.nicholson/SSCLE/SSCLEhome.html>. Web corporativa. Edita la revista Crusades. The journal of the Society for the Study of the Crusades and the Latin East. La sede está ubicada en el Dept. of History, Queen Mary and Westfield College, University of London.

- The Society for Medieval Archaeology <http://www.socmedarch.org/>. Asociación dedicada a IDS estudios arqueológicos de las Islas Británicas para el periodo comprendido entre los siglos V-XVI. Es editora de Medieval Archaeology. Dispone de un directorio de enlaces especializados en arqueología.

\subsection{Departamentos universitarios}

- Departamento de Historia I y Filosofía de la Universidad de Alcalá de Henares que comparte las áreas de Ciencias y Técnicas Historiográficas, Historia Antigua e Historia Medieval < http://www2.uah.es/historia1/>. Información departamental. 
- Departamento de Historia Medieval y Ciencias y Técnicas Historiográficas de la Universidad de Sevilla < http://www.us.es/dhmcthus/>. Se trata de una de las páginas web más completas de las universidades españolas, que incluye información muy exhaustiva de los proyectos de investigación que se llevan a cabo, así como de las tesis. Además, dispone de un excelente catalogo de recursos de Historia Medieval.

- Departamento de Historia Medieval de la Universidad Complutense de Madrid < http://www.ucm.es/info/media/>. Información departamental.

- Departamento de Historia Medieval de la Universidad de Valladolid <http://www.uva.es/medieval >. Información departamental.

- Departamento de Prehistoria, Arqueología, Historia Antigua, Historia Medieval y Ciencias y Técnicas Historiográficas de la Universidad de Murcia <http://www.um.es/dp-prehistoria-arqueologia-historia/>. Información departamental.

- Departamento de Historia. Áreas de Historia Medieval de la Universidad de Extremadura < http://www.unex.es/historia/mediev.htm>. Información departamental.

\section{CONCLUSIONES}

Después de ver todos estos ejemplos, ya podemos extraer una serie de conclusiones clarificadoras y concluyentes. De entre las cientos de miles de páginas que existen hoy en Internet, el porcentaje de correspondiente a la Edad Media es casi insignificante, sobre todo si lo comparamos con otras etapas, como la Contemporánea. Esta característica entra dentro de una lógica. De todos es conocida la ventaja, no solo desde el punto de vista tecnológico, sino fundamentalmente en la creación de contenidos, que lleva Estados Unidos al resto del mundo, que casi se reduce a Europa. Tanto las asociaciones, como las universidades trabajan continuamente en el desarrollo de portales y páginas con contenidos que tienen que ver con la historia y con la actualidad que afecta a los estadounidenses.

De la información que disponemos para la Historia Medieval habría que seleccionar aquella que verdaderamente aporta contenidos originales y válidos, es decir un porcentaje igualmente pequeño. Incluso para las revistas, si seleccionamos los títulos que permiten la consulta de los artículos, el listado se reduce considerablemente.

En cuanto a la procedencia geográfica de las páginas, sin tener en cuenta la temática destacan las creadas al otro lado del Atlántico, tanto universidades norteamericanas, como sudamericanas, especialmente brasileñas.

Europa, a pesar de que es su historia, no ha comprendido todavía la importancia de Internet como medio para divulgar el conocimiento. Sin embargo, algunos estados del Viejo Continente están fomentando el desarrollo de contenidos ligados a las historias nacionales, como Gran Bretaña, Francia e Italia. 
El modelo español, salvando magníficos y únicos ejemplos, es triste. No se desarrollan contenidos. Varias pueden ser las causas, algunas importantes como la económica y de infraestructura, pero la más preocupante es la falta de interés por Internet. Los investigadores, sobre todos los de renombre, los departamentos, etc., siguen pendientes de proyectar su producción en formato papel. Libros, ensayos, artículos, etc. tienen que cumplir con el trámite prestigioso de llevar el sello de editoriales o revistas de renombre.

El defecto va a acrecentarse irremediablemente. Con la aparición de la ANECA, donde los criterios de evaluación tienden a tener en cuenta determinadas editoriales y revistas, tendrá, entre otras graves consecuencias, la marginación de Internet como medio para difundir la investigación y el conocimiento.

Recordemos, que la información difundida en la web tiene una gran virtud, la de conseguir que el conocimiento tenga un acceso universal. Este privilegio, el de contagiar el saber a la sociedad, parece estar reñido con algunos trámites burocráticos. 